Sādhanā Vol. 39, Part 5, October 2014, pp. 1009-1034. (C) Indian Academy of Sciences

\title{
Damage detection in submerged plates using ultrasonic guided waves
}

\author{
SANDEEP SHARMA $^{1, *}$ and ABHIJIT MUKHERJEE ${ }^{2}$ \\ ${ }^{1}$ Mechanical Engineering Department, Thapar University, Patiala 147 004, India \\ ${ }^{2}$ Department of Civil Engineering, Curtin University, Bentley, Western Australia \\ 6102, Australia \\ e-mail: sksharma@thapar.edu
}

MS received 24 September 2012; revised 26 December 2013; accepted 28 February 2014

\begin{abstract}
This paper describes a non-contact and non-invasive health monitoring strategy for submerged plate structures using guided waves. The structure under consideration is immersed in water and subjected to longitudinal ultrasonic waves at specific angles of incidence using a cylindrical piezoelectric transducer using the surrounding water as coupling medium. Suitable ultrasonic guided wave modes with optimum scanning capabilities have been generated and identified in submerged plate system. Finally, the propagation of selected modes through submerged notched plates is investigated. Sensitivity of leaky waves to the notches has been studied. The methodology would help in identifying damages in the submerged plate structures.
\end{abstract}

Keywords. Ultrasonic; guided waves; dispersion; modes; submerged plates; notches.

\section{Introduction}

Several offshore and marine infrastructural systems involve plate-like members in submerged condition and are often subjected to extreme service and environmental conditions leading to deterioration in the form of corrosion, fatigue cracking and other mechanical degradations. Submerged condition of such structures often makes them inaccessible for various established non-destructive technologies for inspection. If the deteriorations remain unnoticed they may result in catastrophic failures causing huge loss to human life and property. In order to avoid any severe loss of integrity of such structures, real time health monitoring of such members is very important. Several nondestructive evaluation (NDE) techniques have been used over the years to identify damages in structures involving plate-like members. These include magnetic particle inspection, magnetic flux leakage technique, pressure testing, magnetic resonance imagery, laser interferometry, acoustic holography, infrared thermography, acoustic emission, radiography and eddy currents. Most of the approaches require interruption of normal service and removal of

*For correspondence 
the subject structure from submerged condition. The prohibitive out-of-service inspection costs restrict the frequency of such investigations, thus exposing them to a great risk of unnoticed fatal damages. The basic aim of this study is to develop an effective non-invasive in-service inspection technique utilizing ultrasonic guided waves.

Traditionally, ultrasonic bulk waves have been used as a reliable means to monitor the state of health of structures. Bulk wave's travel within the interior of a material away from any boundaries, exhibit a finite number of wave modes and have small wavelengths compared to the dimensions of the object being inspected. But the use of ultrasonic bulk waves is limited due to its inability to quickly scan large domains. For applications involving large area inspection in a quick way, guided waves have been suggested by various researchers as an effective tool especially in discovering hidden anomalies (Sharma \& Mukherjee 2010, 2011). Guided waves have the characteristic ability to propagate over long distances and hence may quickly provide global information. They exhibit strong penetration, fast propagation, omni-directional dissemination, convenience of activation and acquisition, inexpensive implementation and most importantly, high sensitivity to structural damage and material inhomogeneties even when they are small in size or lie beneath the surface (Guo \& Kundu 2001). Due to these unique propagation characteristics, Lamb waves were used for damage detection and inspection on a variety of applications like strips and plates, boiler and heat exchanger pipes, K-joints in offshore structures and plate assemblies (Nagy et al 1986; Rose et al 1986; Alleyne \& Cawley 1991, 1992; Ghosh et al. 1998; Ditri \& Rose 1994). But in all these works, the subject structure is placed in air and transducers are required to be in contact with the structure being monitored.

Owing to the several practical limitations in direct contact approach and to exploit mode specific behaviour of Lamb waves to advantage, some researchers have suggested local water column as an effective means to couple the structure with the transducer (Ghosh et al 1998; Guo \& Kundu 2001). The research group designed special set-ups using coupler mechanism and transducer holder capable of generating desired Lamb wave for inspecting defects in large plate structure and underwater pipes.

Although using Lamb waves is a quick and effective means of health monitoring, its interpretation can be a challenge. So, it is very important to understand the key impediments of using the Lamb waves as potential health monitoring tool viz.- - dispersive behaviour of various modes and presence of multiple modes for a given frequency and plate thickness.

Guided Lamb wave modes can be predominantly excited (while subduing other modes) by offering the longitudinal incident ultrasonic wave obliquely to the plate at a particular angle of incidence. This can be accomplished by using - 'Variable Angle Probes' and 'Immersion Coupling'. The former technique is a contact type arrangement, in which a variable angle probe riding on lateral surface of a Perspex semi-cylinder transmits energy into the subject structure. The Perspex block is coupled to the plate by a thin layer of gel. But the measurements can be unreliable due to the inadvertent variations in the contact pressure and couplant thickness. However, immersion coupling avoids these issues and enables contact free data acquisitions.

In case of submerged structures, the presence of water makes the situation unique and challenging as it acts as a natural couplant. In the present work, it is proposed to use 'Immersion coupling' wherein the surrounding water acts as a carrier of incident energy from the probe to the plate. In order to excite a specific Lamb wave mode, a transmitter probe inclined at a specific angle injects incident energy in the plate. The receiver is also placed in the same orientation as the transmitter. In this arrangement the receiver is most sensitive to the wavelength of the mode being input. It results in the receiver highlighting the preferred mode and suppressing the others. The objective of the present work is to study the propagation of ultrasonic guided waves through a submerged plate with notches. 


\section{Experimental investigations}

\subsection{Set-up and specimen details}

The set-up consists of an acrylic tank $(1500 \mathrm{~mm} \times 1000 \mathrm{~mm} \times 900 \mathrm{~mm})$ filled with water up to $750 \mathrm{~mm}$ height. The ultrasonic transducers are fitted in holder arrangements that have four degrees of freedom $(\mathrm{X}, \mathrm{Y}, \mathrm{Z}, \theta)$ (figure 1). The drive consists of three stepper motors with $1.8^{\circ}$ step angles controlling the motions. The motors are individually controlled by a microprocessor unit operated through a user interface. Two motor drives are used for regulating the inter-probe distance along Y-direction by moving the two probes independently (Y-DOF). The third motor unit is dedicated for moving both the probes simultaneously in X-direction, thus scanning the specimen in X-direction (X-DOF). Using XY drive all locations on the submerged plate can be approached by any of the two probes.

Another important feature of the set-up is a Digital Read Out (DRO) system, which provides the user the current $\mathrm{X}$ and $\mathrm{Y}$ coordinates of the probe with respect to the user defined origin. Both the probes can also be independently adjusted manually in Z-direction (Z-DOF). In addition to this, probes can also be set at desired angle with respect to the vertical $(\theta-$ DOF, least count 0.1 degree). It enables the probes to be placed obliquely at required angle of incidence to the specimen.

For ultrasonic testing, a typical UT system consisting of a Pulser-Receiver (PR) device (JSR make, Model DPR 300), ultrasonic transducers (Parametrics ${ }^{\mathrm{TM}}$ Immersion Probes), data acquisition card (Agilent Make) and display devices have been used (figure 2a, b). The subject steel plate $(1065 \mathrm{~mm} \times 610 \mathrm{~mm} \times 4 \mathrm{~mm})$ supported on wooden blocks is completely immersed in the water tank. Two pairs of immersion probes (Olympus Make) with rated frequencies of 0.5 and $1 \mathrm{MHz}$ have been used for the investigation. Selection of frequencies of 0.5 and $1 \mathrm{MHz}$ for initial investigation is based on the principle of lesser material attenuation, scattering and mode

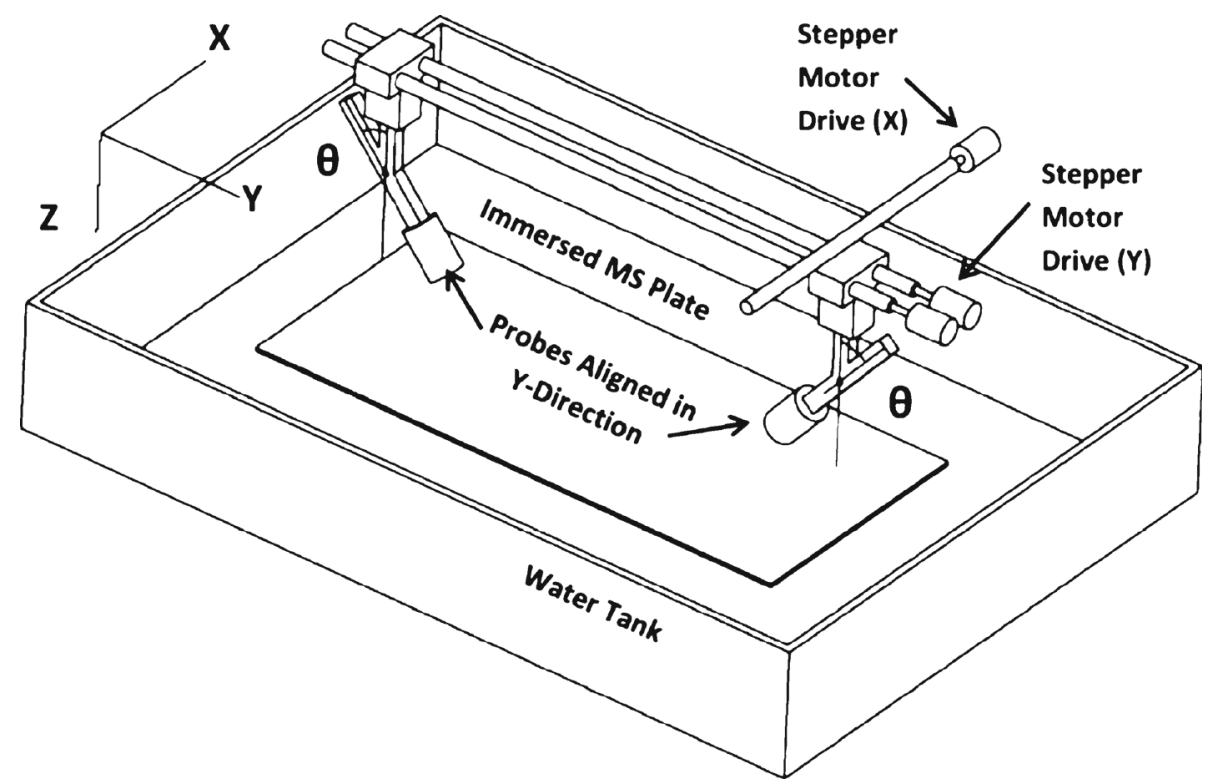

Figure 1. Scanning set-up. 
(a)
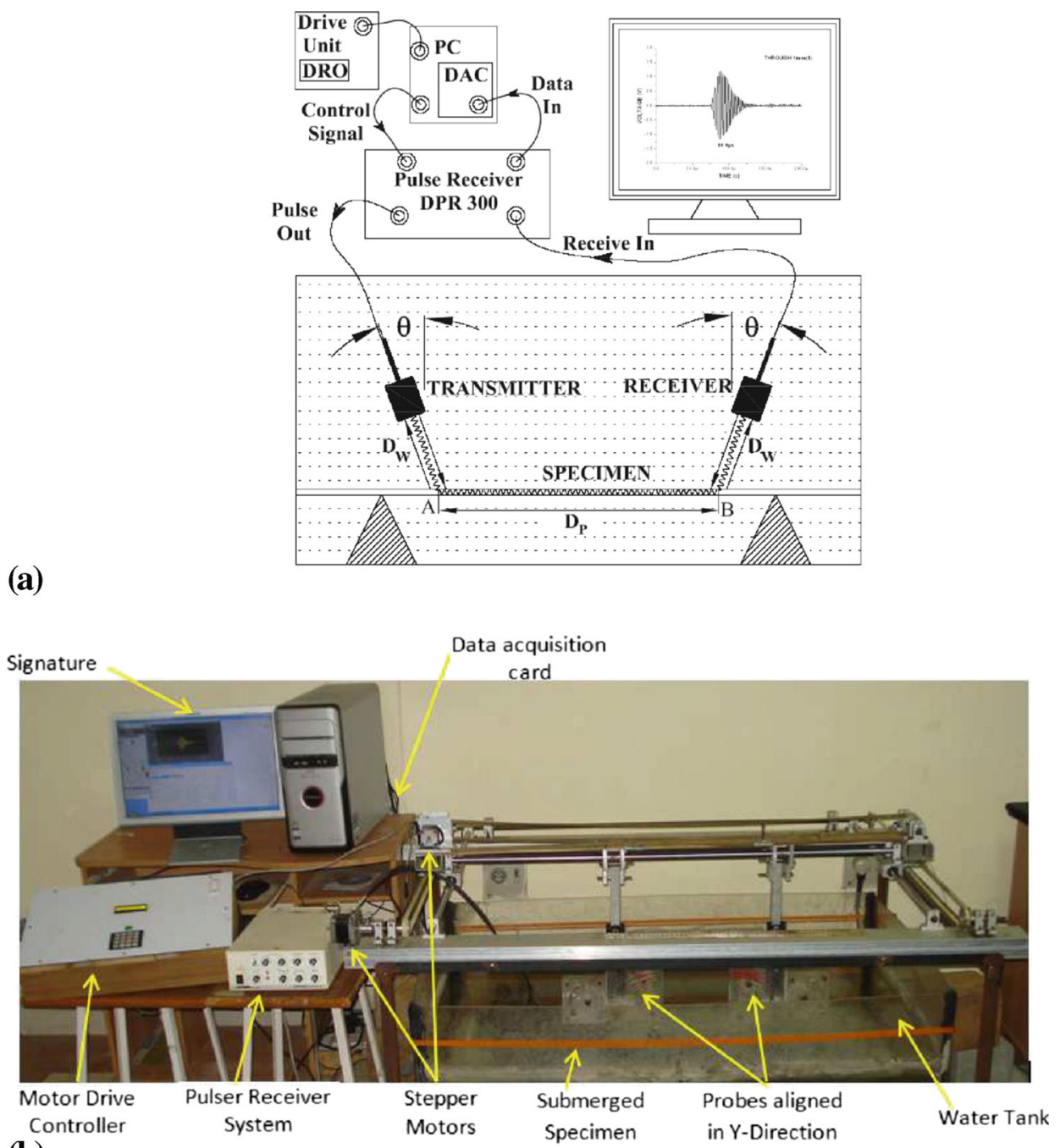

(b)

Figure 2. Experimental set-up. (a) Schematic arrangement, (b) actual photo.

conversions at lower frequencies (Alleyne \& Cawley 1992; Ghosh et al 1998; Rose 2002a, b, 2003).

\subsection{Ultrasonic wave propagation in immersed plates}

The present study focuses on the propagation of ultrasonic waves through the immersed plate for developing a non-contact damage monitoring strategy. For this purpose, the probes and the specimen are immersed in water. The probes are placed in pitch catch orientation, at a distance from the immersed plate and making equal inclinations $(\theta)$ with vertical (figure $2 \mathrm{a}$ ). A vertical gap is maintained between the probes and the immersed plate so as to make the system non-contact. The longitudinal ultrasonic waves generated by the transducers travel through the 
surrounding water and impinge the submerged steel plate obliquely. This input energy is partly reflected and is partly transmitted into the plate. In the pulse echo (PE) mode reflected waves are received by the probe. Distance of separation $\left(D_{w}\right)$ of the probes from specimen is termed as Water Path (figure 2a), as it is the distance travelled by longitudinal wave in water before the wave hits the solid interface. Figures 3(a-d) show PE signatures for both the probes set at a particular angle for the two selected frequencies of 0.5 and $1 \mathrm{MHz}$, respectively. It may be noted that the time of flight in these signatures is kept the same by adjusting Dw.Water path $\left(\mathrm{D}_{\mathrm{w}}\right)$ can be related to the time of flight in water $\left(\mathrm{t}_{\mathrm{w}}\right)$ of the first reflection from the specimen in pulse echo configuration

$$
D_{w}=\frac{t_{w} \times V_{w}}{2}
$$

where

$\mathrm{V}_{w}$ is the longitudinal velocity of the sound in water.

Too large a waterpath results in loss of incident energy to the surrounding water. On the other hand, if the probes are placed too close to the plate, field reflections from the solid interface overlaps with the initial pulse of the transducer. Also the near field effects influence the received signal. A number of trials were undertaken to obtain the suitable water path. Time of flight in

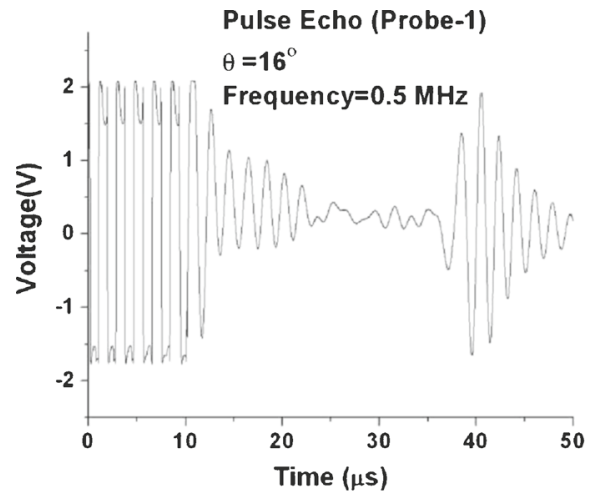

(a)

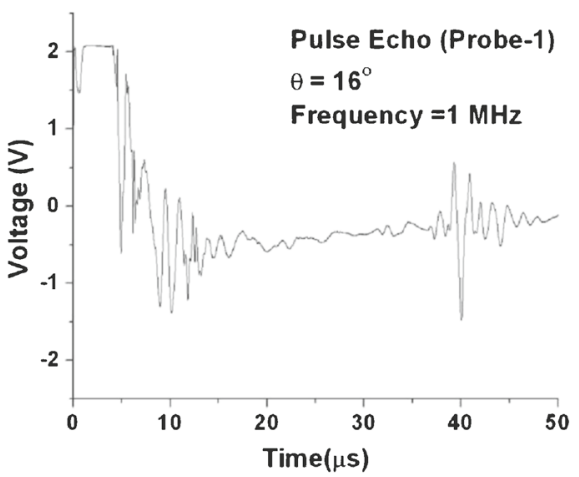

(c)

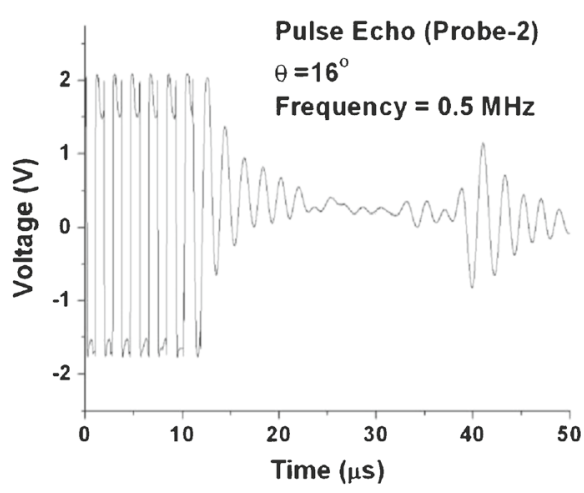

(b)

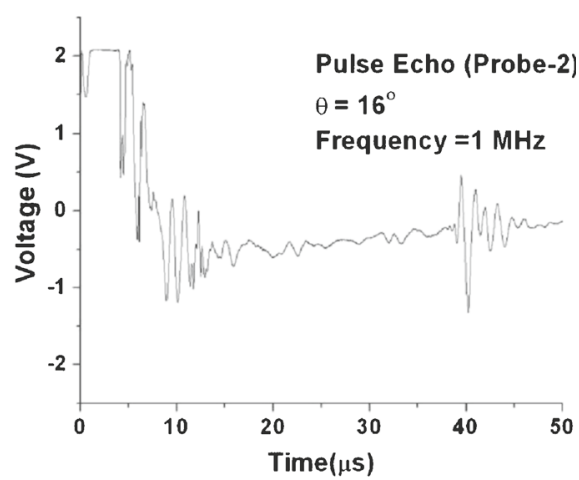

(d)

Figure 3. Pulse echo signatures at $\theta=16^{\circ}$ (a-b) $0.5 \mathrm{MHz}$, (c-d) $1 \mathrm{MHz}$. 
water $\left(t_{\mathrm{w}}\right)$ in the range of $40-50 \mu$ s gives satisfactory results in terms of signal fidelity and repeatability. Thus, in the entire experimental investigations $t_{w}$ is kept at $40 \mu$ s for both the probes.

After setting the probes, ultrasonic testing of the immersed specimen has been carried out in pulse transmission (PT) configuration. The input energy is transmitted into the plate and is guided by the plate geometry to propagate further in the solid media. Guided waves propagating through the immersed plate continuously loose energy to the surrounding water. These leaky guided waves are captured by the receiver probe. These pulses are further conditioned by the PR unit and are displayed on the screen. The distance traversed by the guided waves through the plate is termed here as Propagation distance $\left(D_{p}\right)$. Figures $4 \mathrm{a}$ and $\mathrm{b}$ show the PT signatures obtained using 0.5 and $1.0 \mathrm{MHz}$ probes. Arrival time of the transmitted pulse $\left(\mathrm{T}_{\mathrm{t}}\right)$, comprises of two components namely- $\mathrm{t}_{\mathrm{w}}$ at both transmitter and receiver probes and the time of propagation through the plate $\left(t_{\mathrm{p}}\right)$. PT signature at $0.5 \mathrm{MHz}$ has only one clear peak (figure $4 \mathrm{a}$ ). But PT signature at $1 \mathrm{MHz}$ (figure 4b) has two distinct peaks indicating arrival of two different trains of pulses at the receiver probe, travelling with different speeds.

PT signatures are likely to get affected in the presence of damage on the plate. In the present work, notch damages of varying depths have been inflicted on the immersed plate and corresponding PT signatures have been compared. Figure 5 shows the effect of varying the notch depth on the PT signature using 0.5 and $1 \mathrm{MHz}$ frequencies. It is clear that as the depth of the notch increases the peak to peak voltage amplitude of the received signal drops. Hence, PT technique can successfully identify the notches and possibly quantify the extents. Also, at $1 \mathrm{MHz}$, the left peak corresponding to the faster travelling wave train at $1 \mathrm{MHz}$ is visibly more affected as compared to the peak appearing on the right. It is also evident from figure 5 that the time of arrival of the received pulse remains largely unaltered.

Hence, pulse transmission testing of immersed plate obtained by using non-contact probes exhibit a great potential as a non-destructive investigation tool. The following section describes the effect of variables like angle of inclination $(\theta)$ and propagation distance $\left(D_{P}\right)$ on the transmitted wave signal.

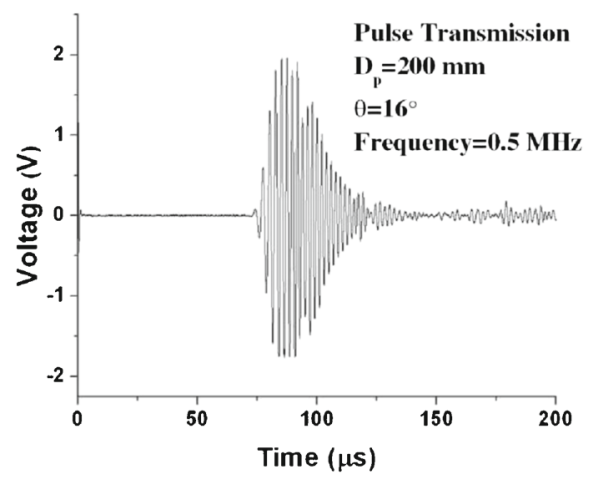

(a)

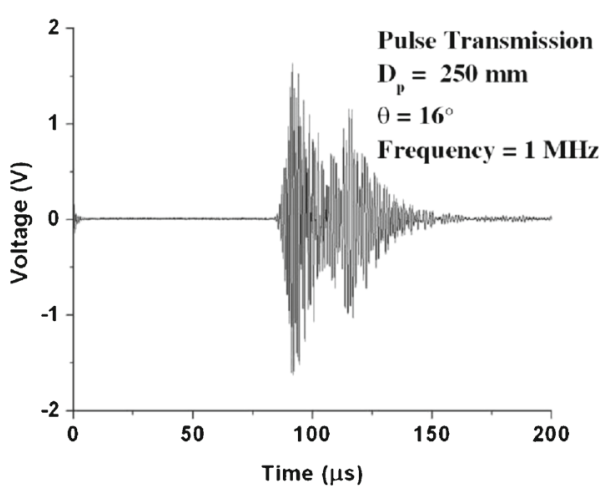

(b)

Figure 4. Pulse transmission signatures - (a) $0.5 \mathrm{MHz}$, (b) $1 \mathrm{MHz}$. 


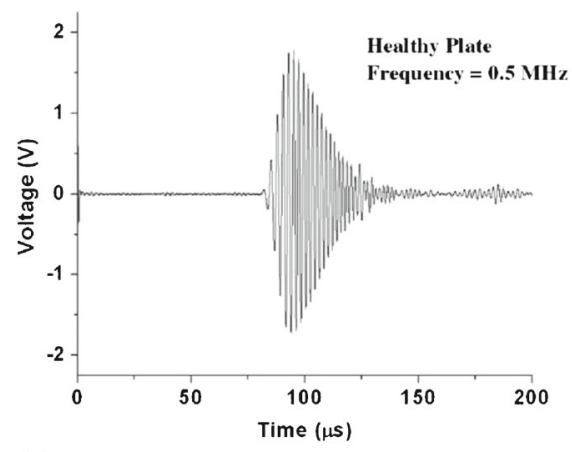

(a)

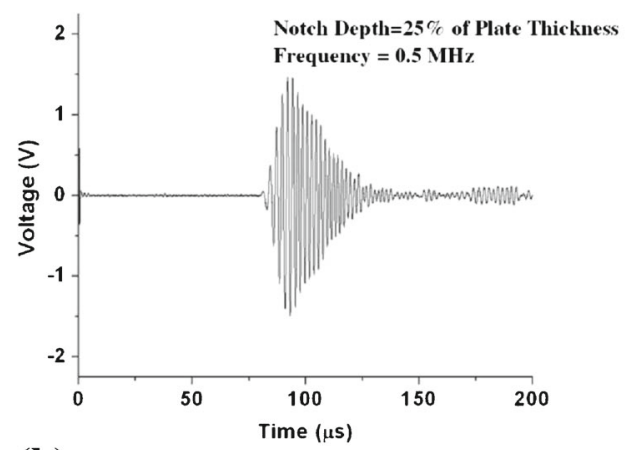

(b)

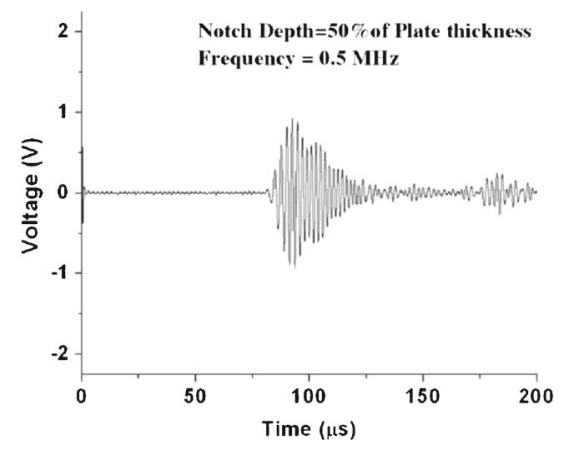

(c)

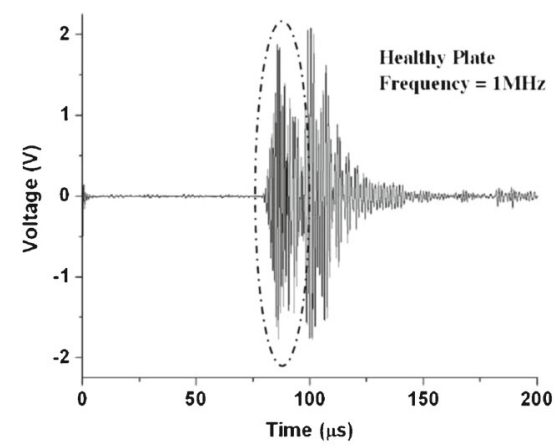

(d)

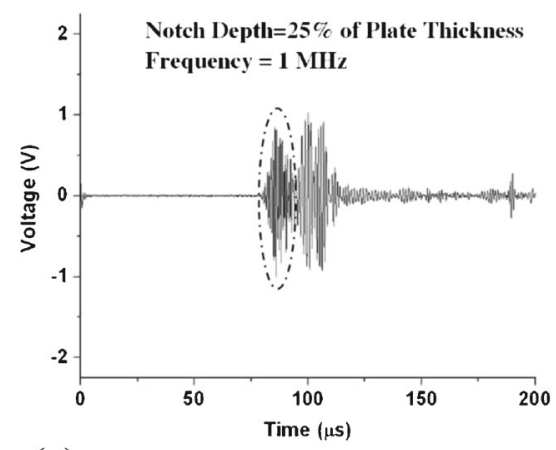

(e)

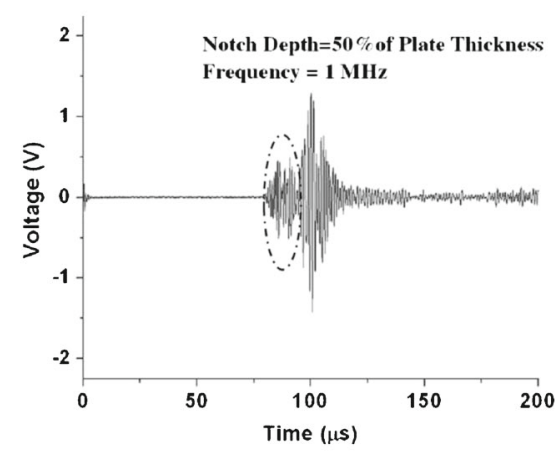

(f)

Figure 5. Effect of notch on PT signatures - (a, b, c) $0.5 \mathrm{MHz},(\mathbf{d}, \mathbf{e}, \mathbf{f}) 1 \mathrm{MHz}$.

\section{Effect of incident angle}

\subsection{Experimental details}

For a given frequency and plate thickness combination, a number of modes can exist in the plate geometry, each one having its independent propagation characteristics like- phase velocity, group velocity and attenuation. Particular modes can be selectively excited by keeping the transmitter and receiver probes at a specified angle of incidence. Objective of this study is to experimentally 
investigate the variation in propagation characteristics of the transmitted pulse with respect to the angle of incidence $(\theta)$ and determine suitable angles of incidence for damage monitoring in submerged plates.

Angles of incidence for both transmitter and receiver probes are varied simultaneously from 0 to $28^{\circ}$ in steps of $2^{\circ}$ and corresponding PT signatures are recorded using frequencies of 0.5 and 1.0 MHz, respectively. During entire experimentation, $\mathrm{t}_{\mathrm{w}}$ has been kept as $40 \mu \mathrm{s}$. Propagation distance $\left(\mathrm{D}_{\mathrm{p}}\right)$ of 200 and $250 \mathrm{~mm}$ have been used for frequencies 0.5 and $1 \mathrm{MHz}$, respectively. PT signatures have been recorded at different locations on the plate specimen in order to ensure consistency and repeatability of the results.

\subsection{Observations and discussions}

3.2a Effect of varying angle: Figures 6 and 7 show the PT signatures obtained at different angles of incidence using 0.5 and $1.0 \mathrm{MHz}$ frequencies, respectively. At $0.5 \mathrm{MHz}$ frequency, when angle of incidence is in the range of $2-6^{\circ}$ (figure $6 a-c$ ), a broad and weak signal is obtained. At $8^{\circ}$, a sharp peak is obtained at $107 \mu$ s $\left(\mathrm{T}_{\mathrm{t}}\right)$. For 10 and $12^{\circ}$ angles, this peak becomes even sharper and appears at 104 and $98 \mu$ s, respectively. Additionally, traces of another smaller amplitude peak on the left side can be seen at about $83 \mu \mathrm{s}$. As $\theta$ increases to 14,16 and $18^{\circ}$, the peak on the left gets stronger and appears at around $90 \mu \mathrm{s}$, whereas the earlier peak on the right side (at $107 \mu \mathrm{s})$ gets fainter and finally disappears. With further increase in $\theta\left(20^{\circ}\right.$ and beyond) all peaks gradually diminish figure 6(1).

At $1 \mathrm{MHz}$ frequency and angle of incidence $4^{\circ}$ (figure $7 \mathrm{a}$ ), a broad and weak signal is obtained. Subsequently at $6^{\circ}$, peak formation starts at $119 \mu \mathrm{s}$. With further increase in angle of incidence $\left(8-12^{\circ}\right.$ range), the peak grows in magnitude and begins to split in to two peaks. This separation is further enhanced at $14-16^{\circ}$ where two distinct peaks can be clearly seen at 91 and $117 \mu \mathrm{s}$. At $18^{\circ}$ these peaks vanish abruptly resulting in a broad and weak signature. At higher values of $\theta$, a weak but relatively sharper peak appears. It grows in size and keeps shifting leftwards with increase in $\theta$ (ranging from 22 to $28^{\circ}$ ).

These signatures clearly indicate that for a selected frequency of excitation and plate geometry, the propagation characteristics like voltage amplitude and time of arrival of the transmitted pulse are substantially influenced by varying the angle of incidence. Figure 8( $a$ and $b$ ) shows the plot of $\mathrm{V}_{\mathrm{p}}$ at different angles of incidence for 0.5 and $1.0 \mathrm{MH}$, respectively. It clearly indicates distinctive bands in $\mathrm{V}_{\mathrm{p}}-\theta$ plots where signal fidelity is best and this range can be further exploited for investigation of submerged plates.

At $0.5 \mathrm{MHz}$ frequency (figure $8 \mathrm{a}$ ) there are two ranges of angles of incidence $\left(9-11^{\circ}\right.$ and $15-$ $17^{\circ}$ ) at which $V_{p}$ of the transmitted pulse is distinctively higher. It is highest at $15-17^{\circ}$ range. Similarly, at $1 \mathrm{MHz}$ frequency (figure $8 \mathrm{~b}$ ), for angles $12-16^{\circ}, \mathrm{V}_{\mathrm{P}}$ is higher. The variations in $\mathrm{V}_{\mathrm{p}}$ with incidence angle can be explained theoretically by plotting dispersion curves for the system.

3.2b Mode identification using dispersion curves: The dispersion curves showing the variation of phase velocities $(\mathrm{km} / \mathrm{s})$, group velocities $(\mathrm{km} / \mathrm{s})$ and attenuation characteristics $(\mathrm{dB} / \mathrm{m})$ with respect to frequency $(\mathrm{MHz})$ for $4 \mathrm{~mm}$ steel plate completely submerged in water have been plotted using Disperse (Pavlakovic \& Cawley 2000) (figure 9). From the phase velocity dispersion curves (figure $9 \mathrm{a}$ ), at $0.5 \mathrm{MHz}$, two Lamb wave modes $\mathrm{S}_{0}$ and $\mathrm{A}_{1}$ exist with phase velocities of 5.02 and $9.75 \mathrm{~km} / \mathrm{s}$, respectively. Similarly at $1 \mathrm{MHz}$, three Lamb wave modes exist, namely $\mathrm{S}_{0}, \mathrm{~S}_{1}$ and $\mathrm{A}_{1}$ with phase velocity $3.14,5.93$ and $5.23 \mathrm{~km} / \mathrm{s}$, respectively. In order to 


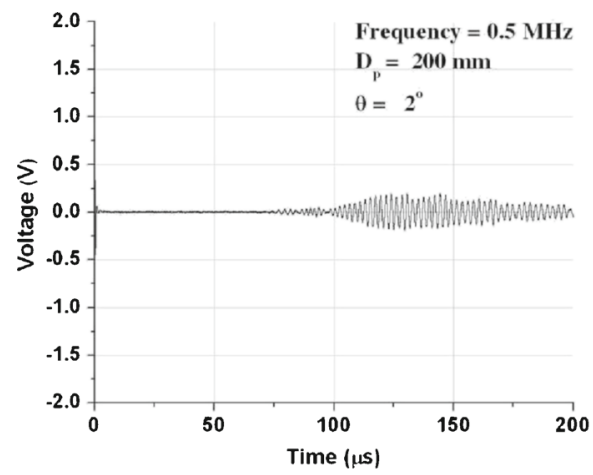

(a)

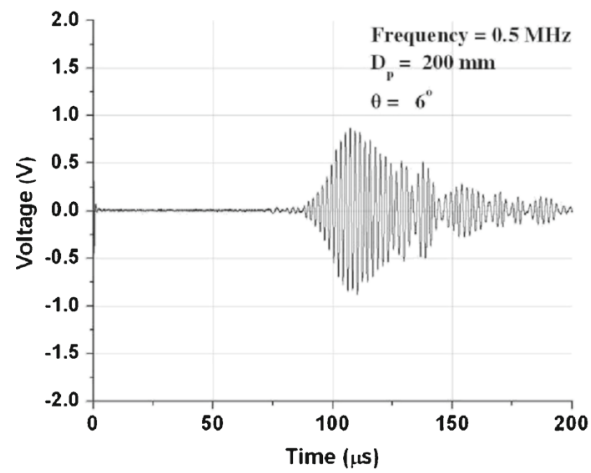

(c)

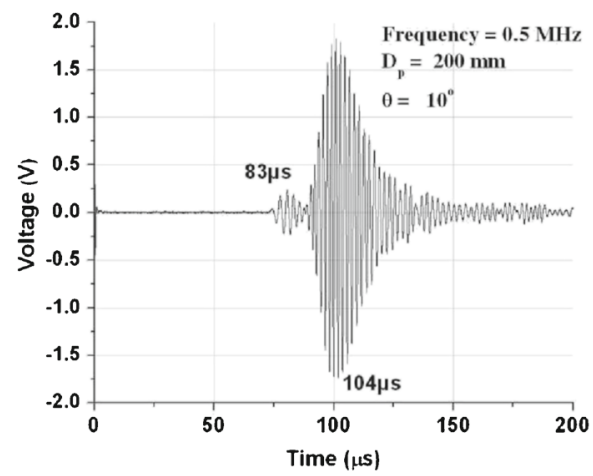

(e)

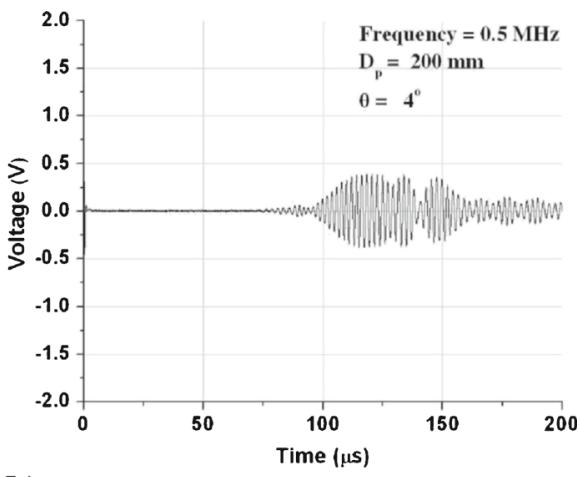

(b)

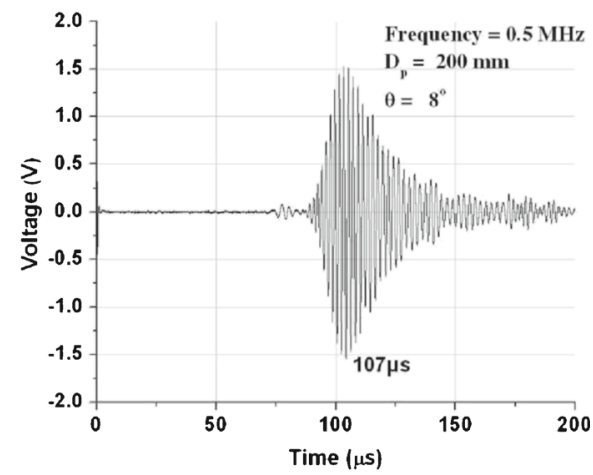

(d)

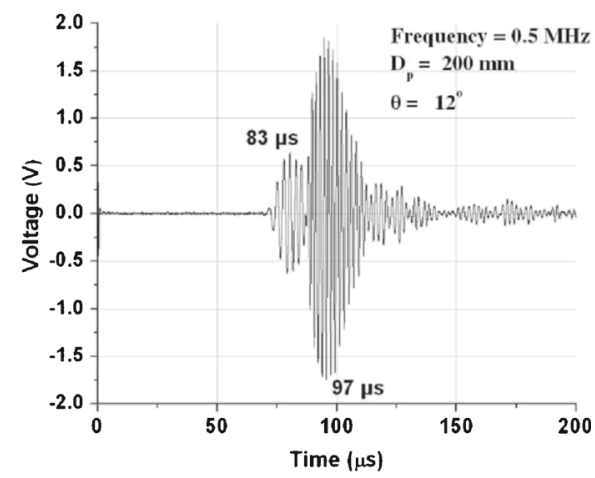

(f)

Figure 6. Pulse transmission signatures using $0.5 \mathrm{MHz}$ frequency for varying angles of incidence.

predominantly excite any of these Lamb wave modes, the longitudinal waves from the transmitter need to impinge the submerged plate at an appropriate angle of incidence (table 1) given by Snell's law.

$$
\theta=\sin ^{-1}\left(\frac{V_{w}}{V_{P h}}\right)
$$




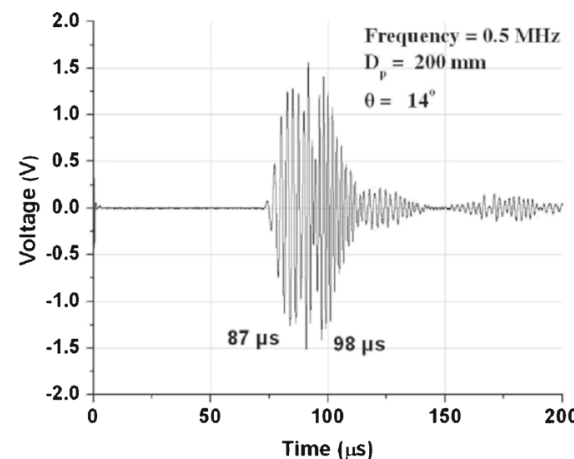

(g)

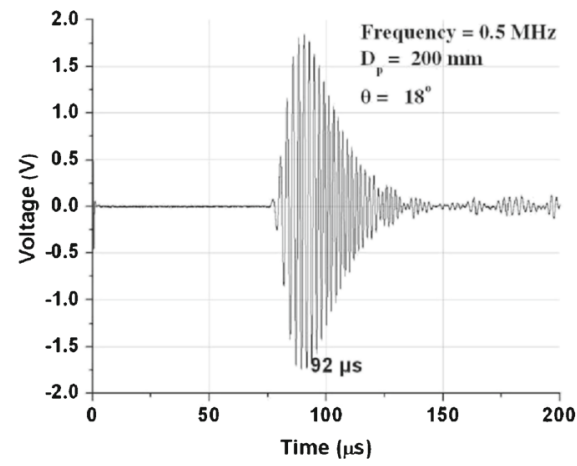

(i)

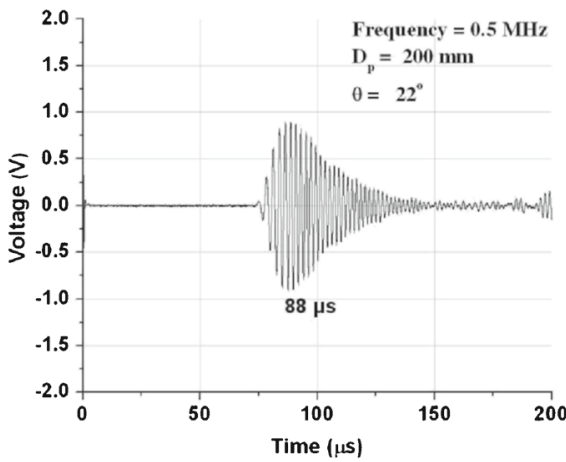

(k)

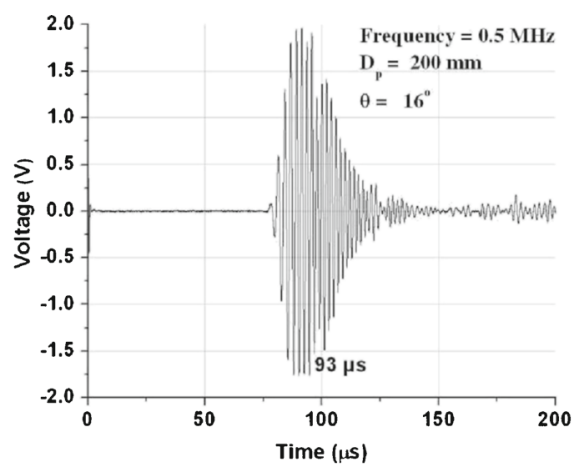

(h)

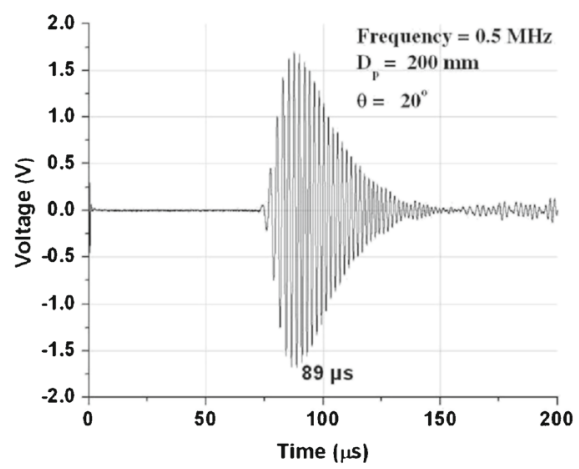

(j)

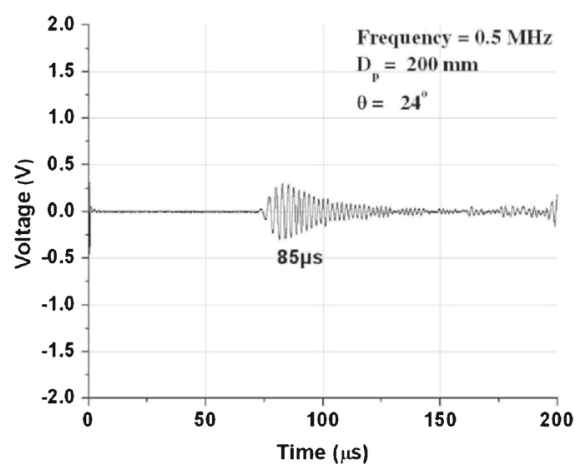

(l)

Figure 6. (continued)

where

$\mathrm{V}_{\mathrm{w}}=$ Longitudinal velocity of the incident wave in the water $(1.5 \mathrm{~km} / \mathrm{s})$.

$\mathrm{V}_{\mathrm{Ph}}=$ Phase velocity of the corresponding Lamb Wave mode from dispersion curves (figure 9a).

In experimental studies, at $0.5 \mathrm{MHz}$ frequency, when the angle of incidence is in range 8$10^{\circ}$ (figure $6 \mathrm{~d}$ and e), the sharp peaks appearing at 107 and $104 \mu$ s indicate the dominance of 


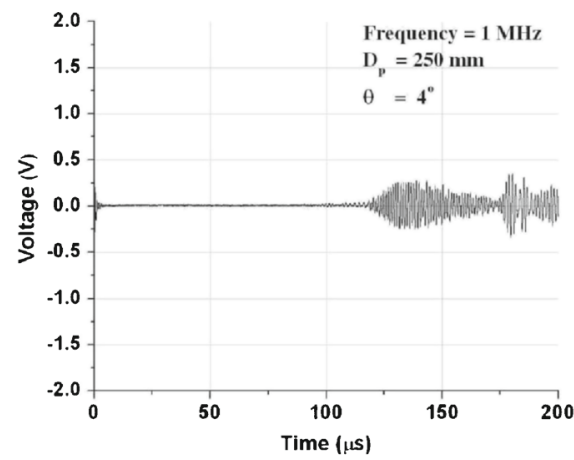

(a)

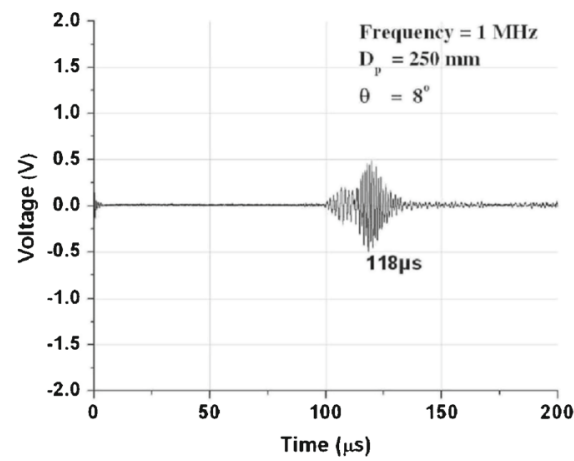

(c)

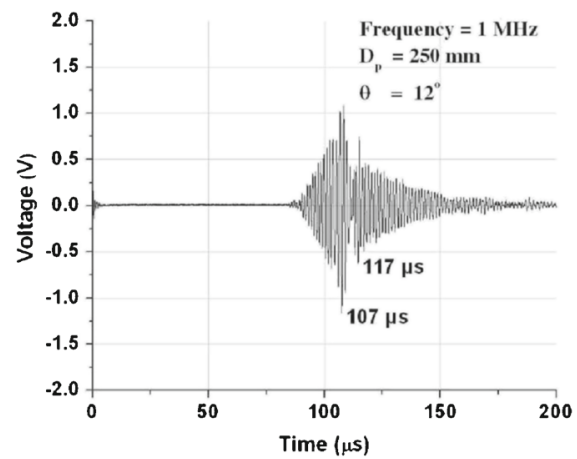

(e)

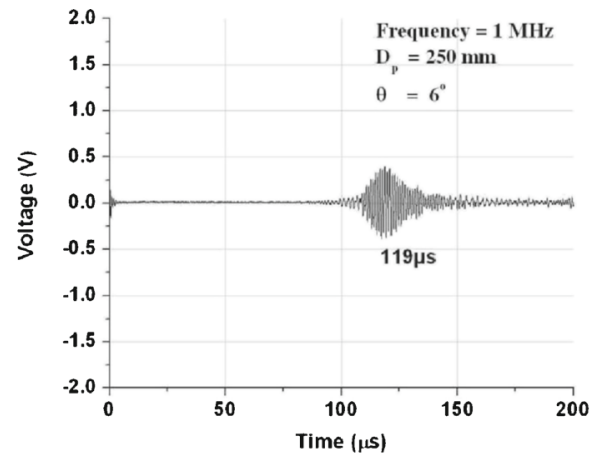

(b)

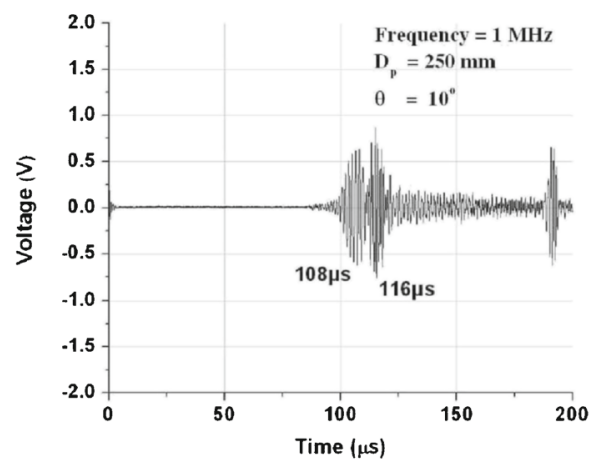

(d)

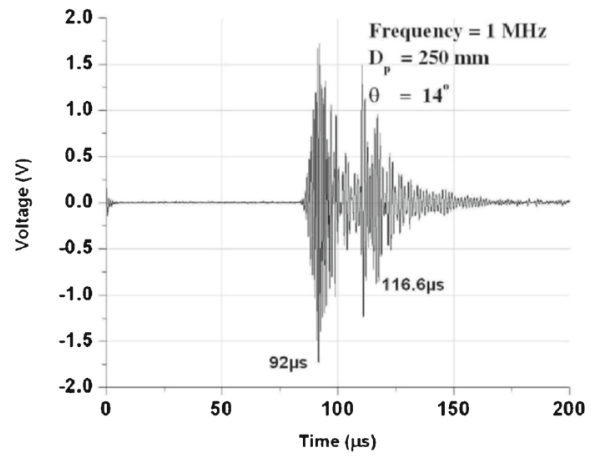

(f)

Figure 7. Pulse transmission signatures using $1 \mathrm{MHz}$ frequency for varying angles of incidence.

$\mathrm{A}_{1}$ mode in this range (table $1, \theta$ for $\mathrm{A}_{1}$ mode is $8.85^{\circ}$ ). Another small peak is visible at $83 \mu$ s which represent the infusion of the traces of $\mathrm{S}_{0}$ mode (table $1, \theta$ for $\mathrm{S}_{0}$ mode is $17.4^{\circ}$ ). Presence of $\mathrm{A}_{1}$ mode can also be verified by matching the experimental arrival time i.e., $107 \mu$ s with the theoretical arrival time. For $t_{w}$ of $40 \mu \mathrm{s}, D_{p}$ of $200 \mathrm{~mm}$ and with group velocity of $3 \mathrm{~km} / \mathrm{s}$ (for $A_{1}$ mode), the theoretical arrival time of the transmitted pulse is $106.6 \mu \mathrm{s}$, which matches closely with the experimentally observed time of arrival of the pulse. 

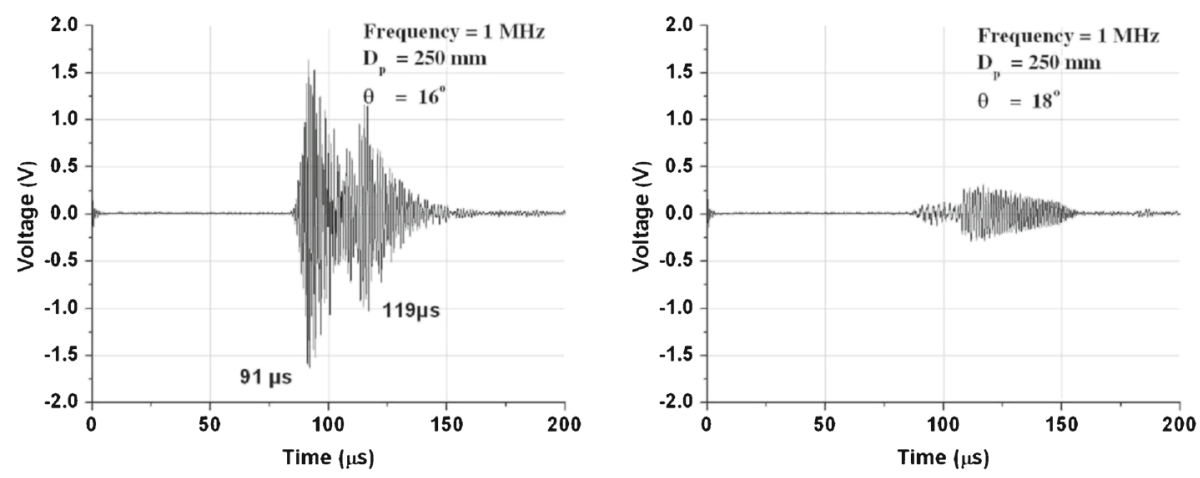

(g)

(h)
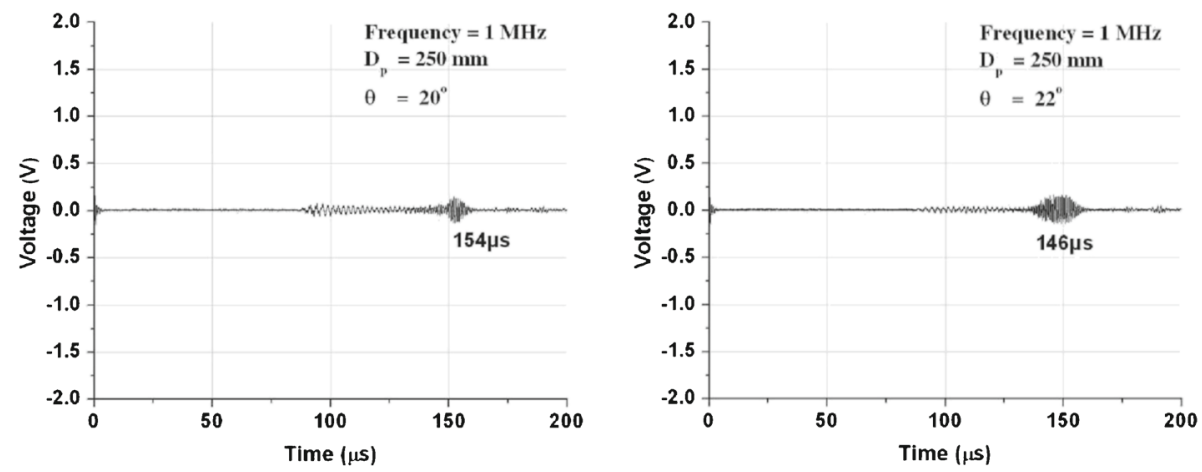

(i)

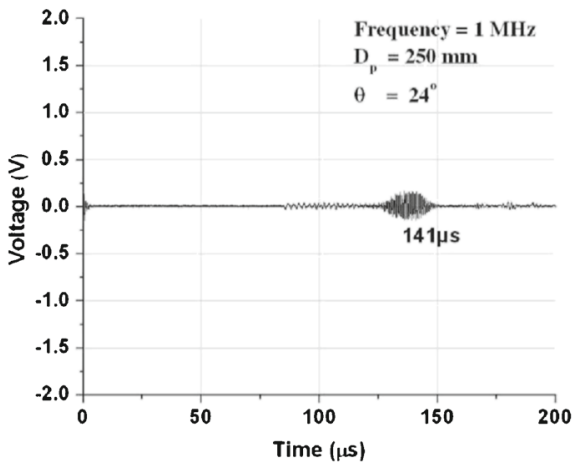

(k)

(j)

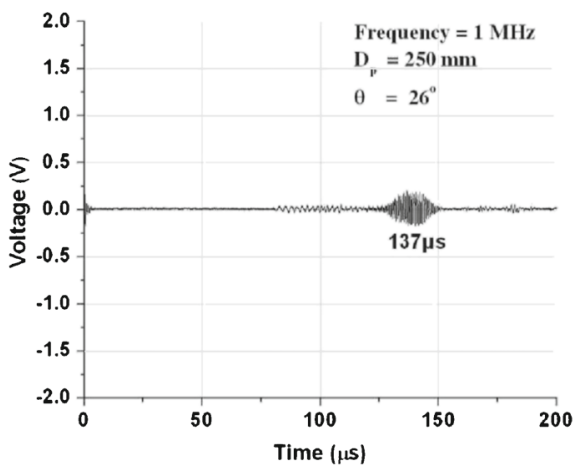

(l)

Figure 7. (continued)

With further increase in $\theta\left(12-14^{\circ}\right)$, the peak corresponding to $\mathrm{A}_{1}$ vanishes and peak corresponding to $\mathrm{S}_{0}$ mode grows in amplitude. At $16-18^{\circ}$, there is a single sharp peak. Presence of $\mathrm{S}_{0}$ mode appearing at $92 \mu \mathrm{s}$ in the signature can also be verified by matching with the theoretical arrival time of the mode. For $\mathrm{t}_{\mathrm{w}}$ of $40 \mu \mathrm{s}, \mathrm{D}_{\mathrm{p}}$ of $200 \mathrm{~mm}$ and with group velocity of $3.75 \mathrm{~km} / \mathrm{s}$ of $\mathrm{S}_{0}$ mode, the theoretical arrival time of the transmitted pulse is $93.2 \mu$ s which matches closely 


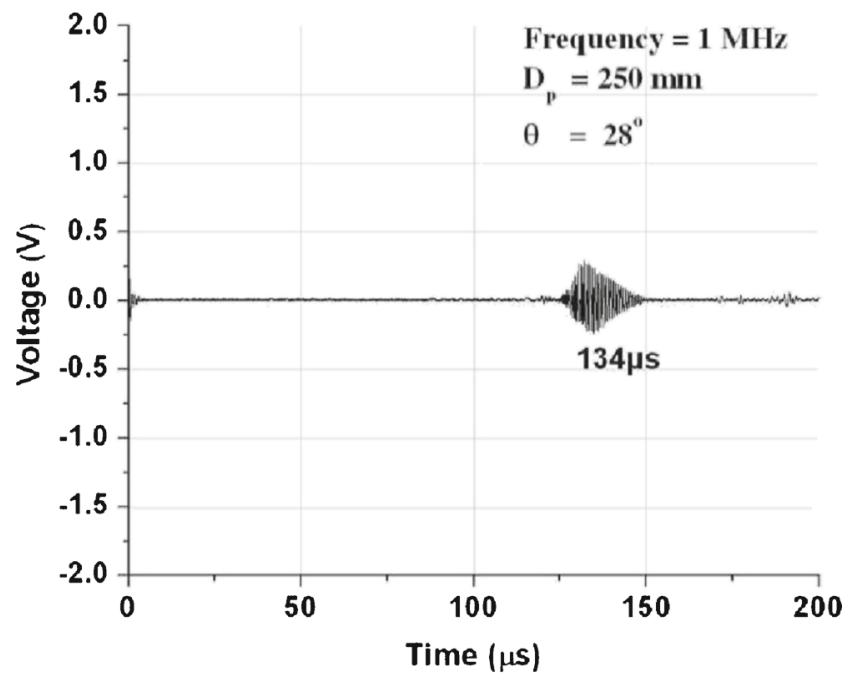

(m)

Figure 7. (continued)

with the experimental arrival time of the pulse. At higher values of $\theta\left(20-24^{\circ}\right)$ this peak vanishes which is also supported by the dispersion curves that no Lamb wave mode is feasible beyond $20^{\circ}$.

Response of $\mathrm{S}_{0}$ and $\mathrm{A}_{1}$ modes at $0.5 \mathrm{MHz}$ with varying probe angle is studied by plotting the voltage amplitude in the PT signatures (figure 6a-1) at corresponding time of arrival (92 and $107 \mu \mathrm{s}$, respectively). It clearly highlights the regions of dominance of these modes. It is clear that figure $8 \mathrm{a}$ is the envelope curve encompassing the effect of all the feasible modes at $0.5 \mathrm{MHz}$.

Hence, for frequency of excitation of $0.5 \mathrm{MHz}$, two modes are feasible i.e., an anti-symmetric mode $\left(\mathrm{A}_{1}\right)$ at $8.85^{\circ}$ and a symmetric mode $\left(\mathrm{S}_{0}\right)$ at $17.4^{\circ}$. Interpretation of the PT signatures

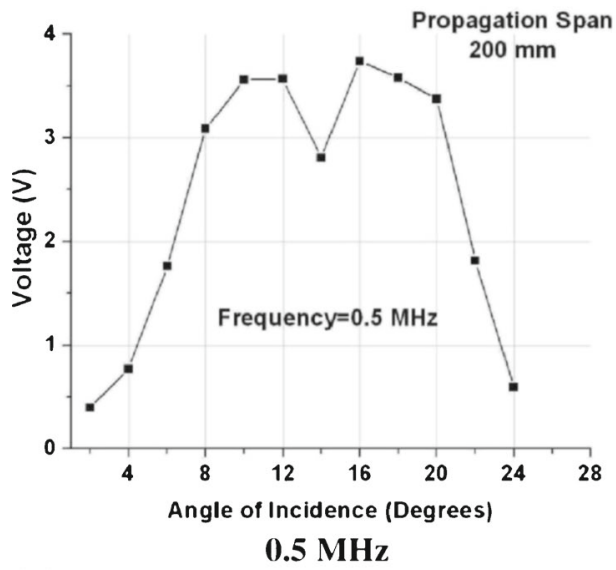

(a)

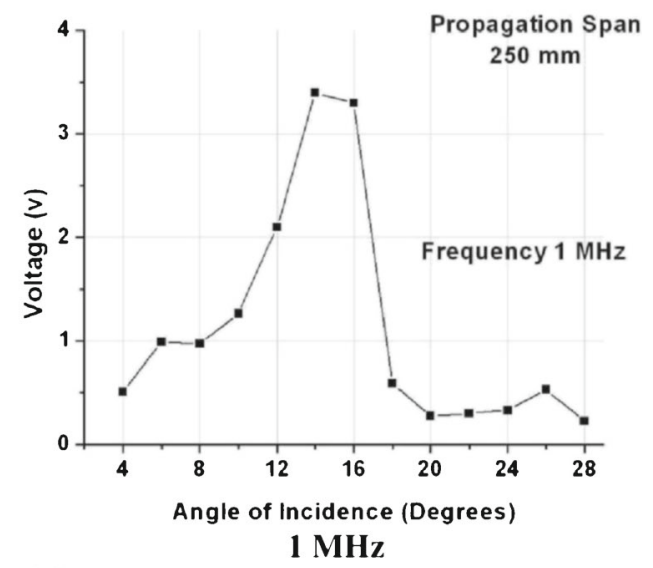

(b)

Figure 8. Angle of incidence $(\theta)$ Vs. $V_{p}$ of transmitted pulse. 


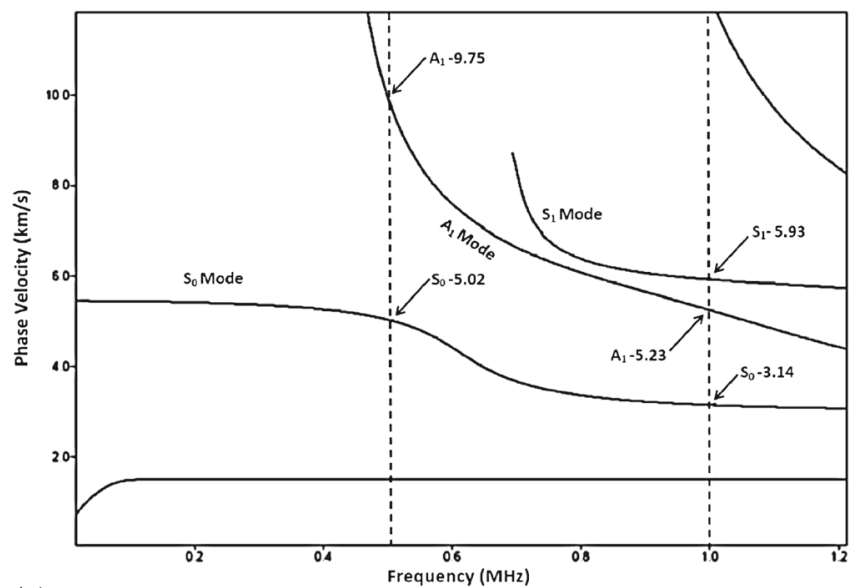

(a)

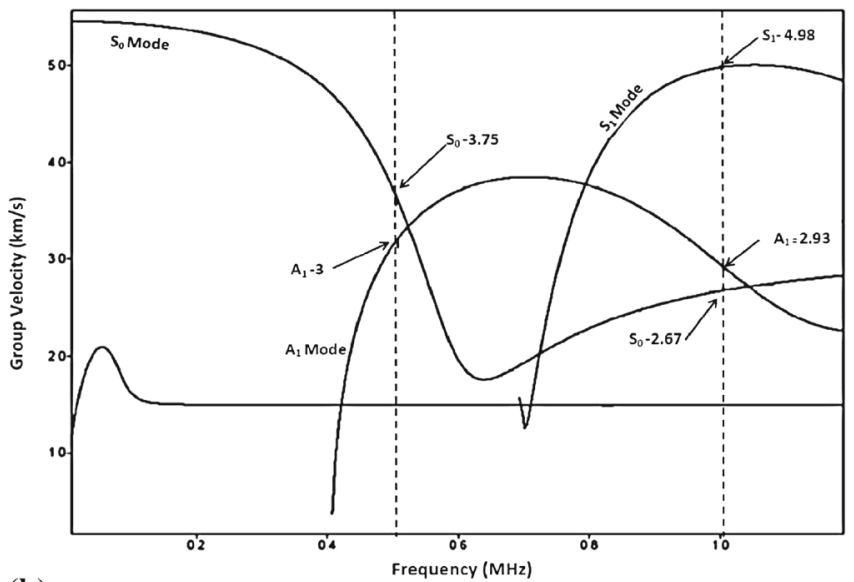

(b)

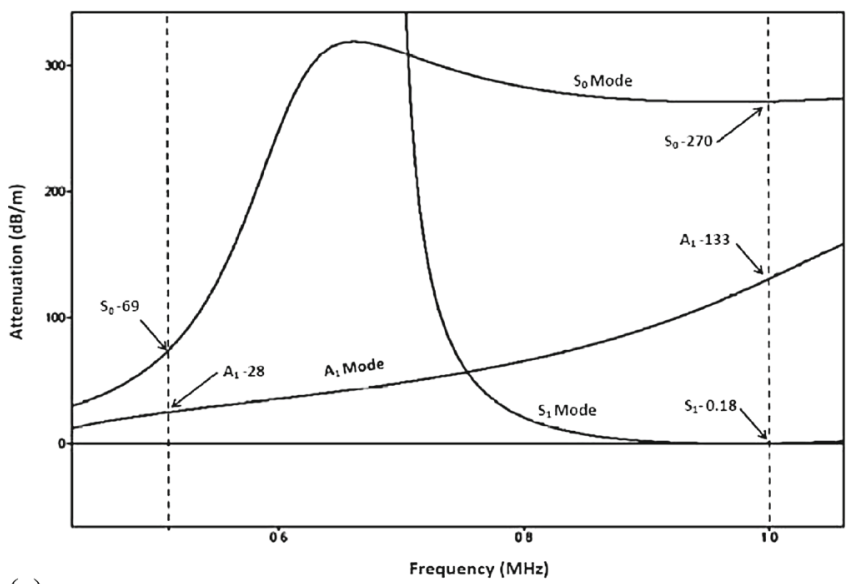

(c)

Figure 9. Dispersion curves for $4 \mathrm{~mm}$ steel plate in water. (a) Phase velocity vs. frequency. (b) Group velocity vs. frequency. (c) Attenuation vs. frequency. 
Table 1. Angle of incidence $(\theta)$ for various Lamb wave modes.

\begin{tabular}{lccc}
\hline Sl. no. & Lamb wave mode & Phase velocity $(\mathrm{km} / \mathrm{s})$ & Angle $(\theta)$ \\
\hline 1 & $\mathrm{~S}_{0}$ at $0.5 \mathrm{MHz}$ & 5.02 & $17.4^{\circ}$ \\
2 & $\mathrm{~A}_{1}$ at $0.5 \mathrm{MHz}$ & 9.75 & $8.85^{\circ}$ \\
3 & $\mathrm{~S}_{0}$ at $1 \mathrm{MHz}$ & 3.14 & $28.5^{\circ}$ \\
4 & $\mathrm{~S}_{1}$ at $1 \mathrm{MHz}$ & 5.93 & $14.7^{\circ}$ \\
5 & $\mathrm{~A}_{1}$ at $1 \mathrm{MHz}$ & 5.23 & $16.7^{\circ}$ \\
\hline
\end{tabular}

corresponding to both the modes is easy due to presence of sharp and well separated peaks. These modes can further be exploited for investigating damage in submerged plates.

Similarly, in PT signature of immersed plate at $1.0 \mathrm{MHz}$ frequency, no clear peak is visible for angles of incidence up to $4^{\circ}$ (figure $7 \mathrm{a}$ ). At $6^{\circ}$, the peak starts appearing at $119 \mu \mathrm{s}$. For $8-16^{\circ}$ the signal contains two well separated peaks centered at $91 \mu$ s and $119 \mu$ s. These two peaks represent the simultaneous presence of two modes in the signal viz. $S_{1}$ and $A_{1}$. It is due to the fact that angles of incidence required for $S_{1}$ and $A_{1}$ modes are 14.7 and $16.7^{\circ}$, respectively (table 1). Presence of $S_{1}$ and $A_{1}$ modes in the signal can also be verified by the comparing the experimental arrival times of the transmitted pulse peaks with the theoretical arrival times. For $\mathrm{t}_{\mathrm{w}}$ of $40 \mu \mathrm{s}, \mathrm{D}_{\mathrm{p}}$ of $250 \mathrm{~mm}$ and with group velocities $4.98 \mathrm{~km} / \mathrm{s}$ (for $\mathrm{S}_{1}$ mode) and $3 \mathrm{~km} / \mathrm{s}$ (for $A_{1}$ mode), the theoretical arrival times of the transmitted pulse are 90.5 and $123.3 \mu$ s for $S_{1}$ and $\mathrm{A}_{1}$ modes, respectively. They match closely with the experimentally observed times of arrival of the pulse for $S_{1}$ and $A_{1}$ modes (91 and $119 \mu$ s, respectively). For higher values of angle of incidence ( $18^{\circ}$ and above) both $\mathrm{A}_{1}$ and $\mathrm{S}_{1}$ modes disappear. This is indicated by the absence of any sharp peak in figure $7(\mathrm{~h}-\mathrm{m})$.

Further, at $20^{\circ}$ there is appearance of a weaker peak at $154 \mu$ s which continuously shifts leftwards with increasing values of $\theta$. This peak exhibits highest amplitude at $28^{\circ}$ and corresponding arrival time is $134 \mu \mathrm{s}$. This peak is attributed to the $S_{0}$ mode as indicated by its time of arrival in PT. Theoretical time of arrival of $134.3 \mu$ s matches closely with experimentally obtained time of arrival of transmitted pulse i.e., $134 \mu$ s.

Voltage amplitude of the received signals (figure $7 \mathrm{a}-\mathrm{m}$ ) corresponding to the arrival times of $S_{1}$ mode $(91 \mu \mathrm{s}), A_{1}$ mode $(123 \mu \mathrm{s})$ and $S_{0}$ mode $(134 \mu \mathrm{s})$ at $1 \mathrm{MHz}$ have been plotted in figure $10 \mathrm{~b}$. This plot shows the regions of dominance of these modes in the V- $\theta$ plot. It is also clear that the curve in figure $8 \mathrm{~b}$ is the envelope curve of all the modal responses.

3.2c Selection of modes: Selection of a particular mode for damage detection is based on; minimum attenuation for maximizing scanning distance, good signal fidelity and the energy distribution profile across the plate thickness. At $0.5 \mathrm{MHz}$ frequency of excitation, the two available modes viz.- symmetric mode $S_{0}$ and anti-symmetric mode $A_{1}$ exhibit well defined sharp peaks at corresponding angles of excitation of 16.7 and $8.85^{\circ}$, respectively. It is due to relatively lesser attenuation experienced by the wave at lower frequencies of excitation (figure 9c). Hence, both the modes at $0.5 \mathrm{MHz}$ are considered for the further experimental investigations.

At a frequency of excitation of $1.0 \mathrm{MHz}$, there are three modes i.e., symmetric mode $\mathrm{S}_{1}$ at $14.7^{\circ}$, anti-symmetric mode $A_{1}$ at $16.7^{\circ}$ and symmetric mode $S_{0}$ at $28^{\circ}$. But $S_{0}$ mode has higher attenuation resulting in extremely low $\mathrm{V}_{\mathrm{p}}(0.51 \mathrm{~V})$ in comparison to $\mathrm{A}_{1}(2.22 \mathrm{~V})$ and $\mathrm{S}_{1}(3.46 \mathrm{~V})$ modes. Also, from dispersion plots (figure 9c) $\mathrm{S}_{0}$ exhibits maximum attenuation of $270 \mathrm{~dB} / \mathrm{m}$. Thus, the amplitude of the resulting peak is too small to be useful for health monitoring purposes. Hence, $\mathrm{S}_{0}$ mode at $1 \mathrm{MHz}$ is discarded. 


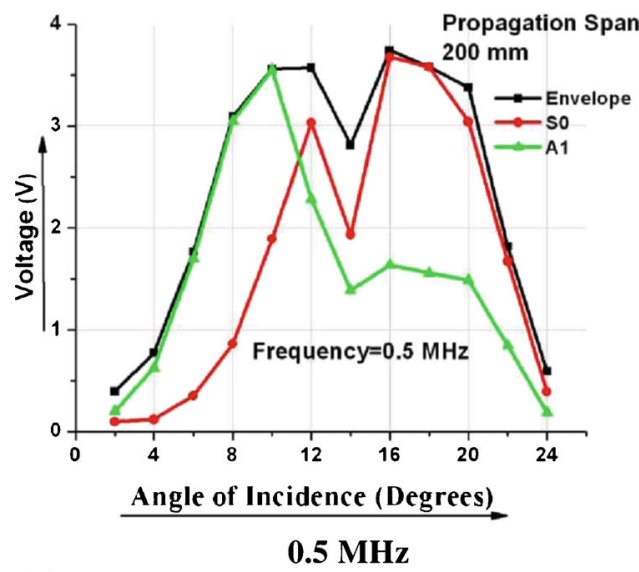

(a)

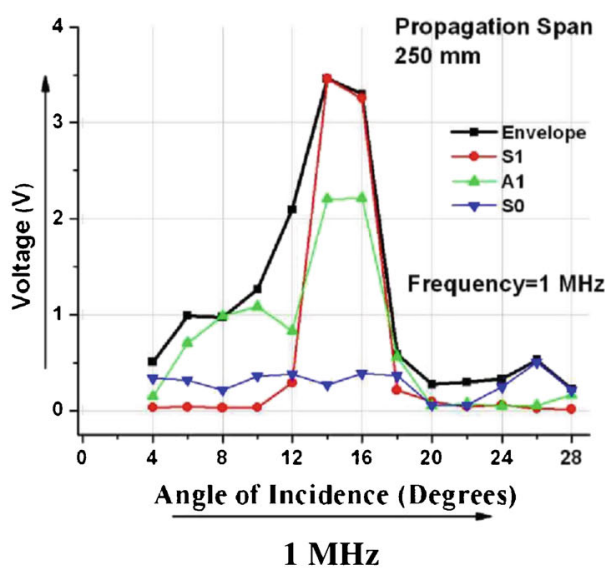

(b)

Figure 10. V- $\theta$ plot for the feasible modes.

Furthermore, anti-symmetric modes $\left(\mathrm{A}_{1}\right.$ in this case) are considered unsuitable for damage detection in submerged conditions due to relatively higher attenuative characteristics (Rose 2003). This is mainly attributed to the effective coupling of the out-of-plane displacement component with the surrounding medium. This is supported by the attenuation dispersion curves (figure 9c). $A_{1}$ mode has higher attenuation of $69 \mathrm{db} / \mathrm{m}$ as compared to $S_{1}$ mode $(0.18 \mathrm{db} / \mathrm{m})$. In addition to this, the group velocities for modes $S_{0}(2.67 \mathrm{~km} / \mathrm{s})$ and $A_{1}(3 \mathrm{~km} / \mathrm{s})$ at $1 \mathrm{MHz}$ are very close. It results in appearance of a number of merging peaks in PT signature due to contributions of traces of $\mathrm{S}_{0}$ mode. So the signal obtained is in the form of an envelope rather than a sharp distinctive peak (figure $7 \mathrm{~h}$ ). It makes interpretation of results difficult.

The phase velocities for modes $A_{1}(5.23 \mathrm{~km} / \mathrm{s})$ and $\mathrm{S}_{1}(5.93 \mathrm{~km} / \mathrm{s})$ at $1.0 \mathrm{MHz}$ are close resulting in close values for angles of incidence (table 1). The 1.0 MHz transducer has a diameter of $25 \mathrm{~mm}$. In such a situation, divergence of the longitudinal wave traversing through the water results in overlap of the angles of incidence. It leads to appearance of twin peaks (figure $7 \mathrm{f}$ and g) indicating simultaneous presence of the two modes. However, these peaks are separated due to difference in their group velocities and the separation increases further with higher values of $D_{p}$. Clearly the peak corresponding to $S_{1}$ mode $(91$ and $92 \mu \mathrm{s})$ is shaper and more identifiable as compared to the other peaks representing $\mathrm{A}_{1}$ mode $(116.6-119 \mu \mathrm{s})$ which has relatively lower voltage amplitude and does not have a clear sharp peak. Owing to these factors, $A_{1}$ mode is not preferred and is rejected for subsequent damage monitoring in submerged plate specimen. Hence at $1.0 \mathrm{MHz}$, only $\mathrm{S}_{1}$ mode is used for subsequent investigations.

$3.2 \mathrm{~d}$ Verification with group velocity: Presence of the various modes at corresponding frequencies of excitation is further verified by matching experimental group velocity of the modes (from PT signatures) and theoretical Group Velocity (figure 9b). Experimental group velocity is calculated as

$$
\text { Group Velocity } \text { Experiment }=\frac{D_{P}}{T_{t}-T_{f}} .
$$

The comparison of the experimental and theoretical group velocities for all feasible Lamb wave modes at 0.5 and $1.0 \mathrm{MHz}$ shows a close match between the theoretical and experimental group 


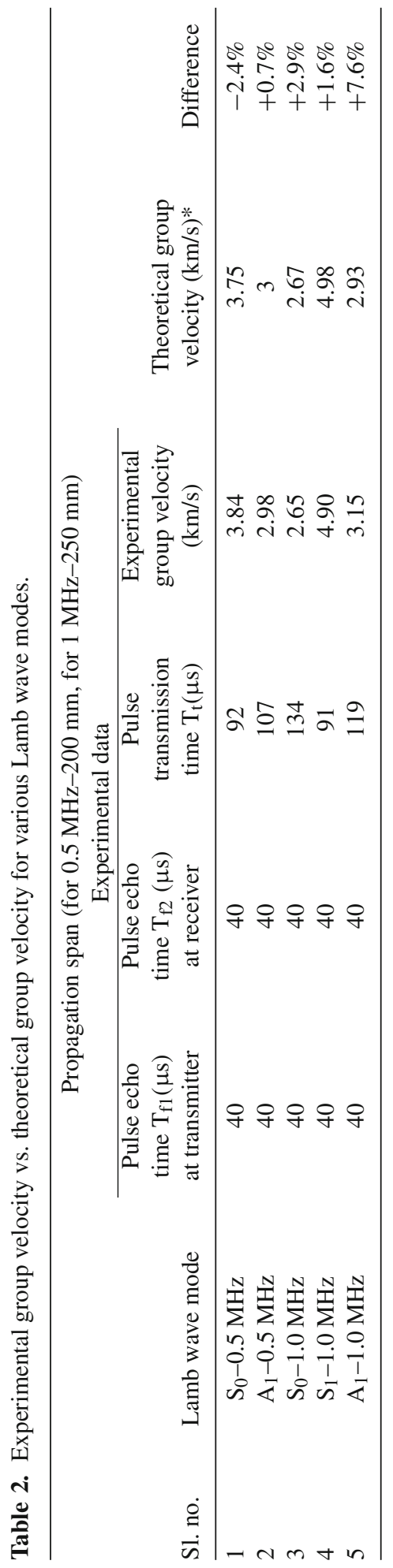


velocities (table 2). The difference may be attributed to the local variations in the plate thickness and material properties.

\section{Effect of obstruction on Lamb wave propagation}

This experimental study has been undertaken to ensure that PT signatures only depict the guided Lamb waves travelling through the submerged plate. Aim of this study is to rule out any possibilities of any undesirable signals like reflections or transmission from other nearby interfaces like water surface in the tank, bottom of the tank, etc. In this study, the specimen remains submerged and another steel plate $12 \mathrm{~mm}$ thick is used as obstruction in different configurations (figure 11). PT signatures corresponding to various configurations experimental data have been recorded for selected $\mathrm{S}_{0}$ mode at $0.5 \mathrm{MHz}$ (figure 12a) and $\mathrm{S}_{1}$ mode at $1 \mathrm{MHz}$ (figure $12 \mathrm{~b}$ ). Near identical PT signatures in figure 12 suggests that the receiver probe captures the Lamb waves travelling through the submerged plate only. Thus, the presence of the obstructing steel plate does not influence the received signal.

Hence, it can be concluded that a particular Lamb wave mode with unique propagation characteristics can be selectively excited with reasonable accuracy in an immersed plate using non-contact systems by orienting the submerged longitudinal probes at suitable angles of incidence. Presence of a particular mode can be confirmed by matching its experimental arrival time (from PT signatures) with theoretical arrival time (from dispersion curves) for a given propagation distance.

\section{Effect of propagation distance}

\subsection{Signal fidelity vis-a-vis propagation distance}

In this section, the effect of propagation distance on signal strength $\left(\mathrm{V}_{\mathrm{p}}\right)$ is studied. At different angles of incidence, $D_{p}$ has been varied from 200 to $300 \mathrm{~mm}$. During this experiment, operating parameters like dB setting, Low Pass Filter (LPF), High Pass Filter (HPF) settings, etc. for the

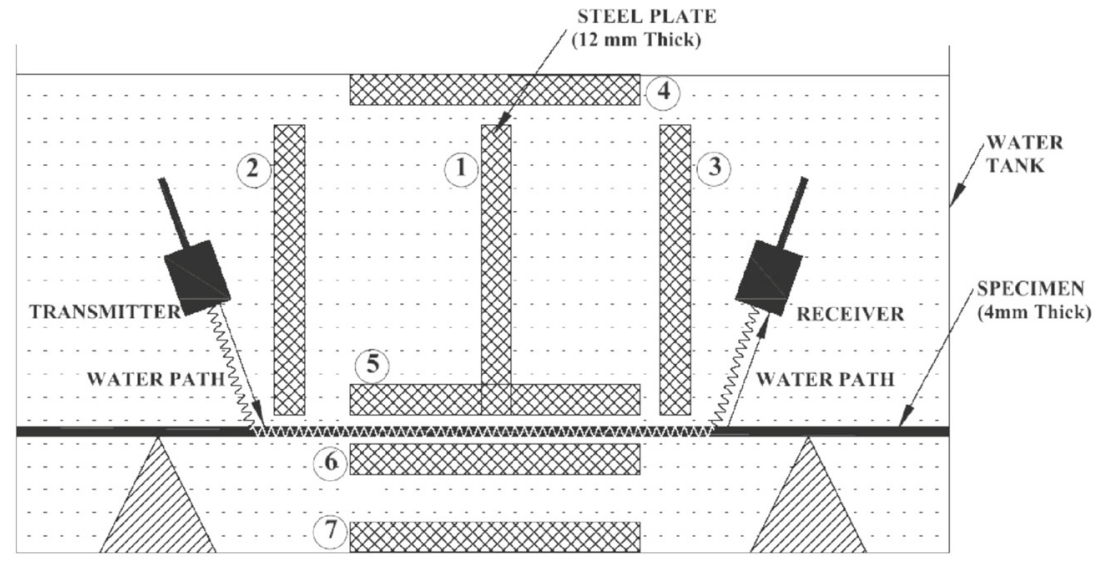

Figure 11. Guided wave propagation with obstruction placed in different configurations. (1)-Midway between the probes; (2)-Near left probe; (3)-Near right probe; (4)-Near water surface; (5)-Just on top of specimen plate; (6)-Just below specimen plate; (7)-Lying on the tank bottom. 


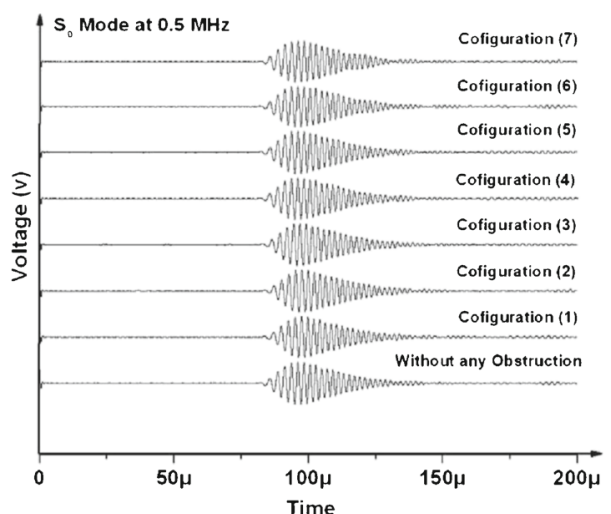

(a)

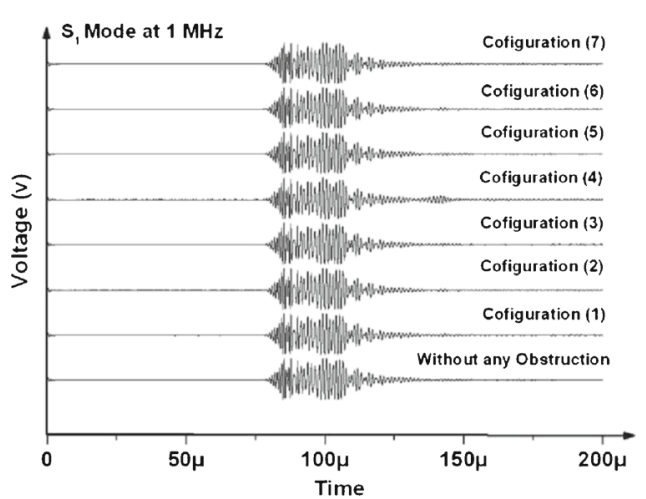

(b)

Figure 12. Pulse transmission signatures for different configurations.

PR unit are kept at the same level to avoid any biasing. It has been observed that for some values of angles of incidence, Lamb waves are too weak to traverse through the span. In such cases no signal is plotted. Figure 13 shows $\mathrm{V}_{\mathrm{p}}$ of transmitted pulse corresponding to the different angles of incidence at variable propagation distances. It clearly suggests that change in the propagation distance has no effect on the trends of transmitted pulse amplitudes (figures 8 and 13). For a given angle of incidence, the amplitude of the transmitted pulse decreases with increase in the propagation distance. This can be primarily attributed to the more leakage of energy into the surrounding water and increased material attenuation due to increased propagation distance.

\subsection{Study on selected modes}

To investigate the optimum scanning capabilities of the selected symmetric Lamb wave modes $\left(\mathrm{S}_{0}\right.$ at $0.5 \mathrm{MHz}$ and $\mathrm{S}_{1}$ at $1 \mathrm{MHz}$ ), the transmitter and receiver probes are set at respective angles in pitch catch configuration. Initially, the probes are set to have a propagation distance $\left(D_{p}\right)$ of

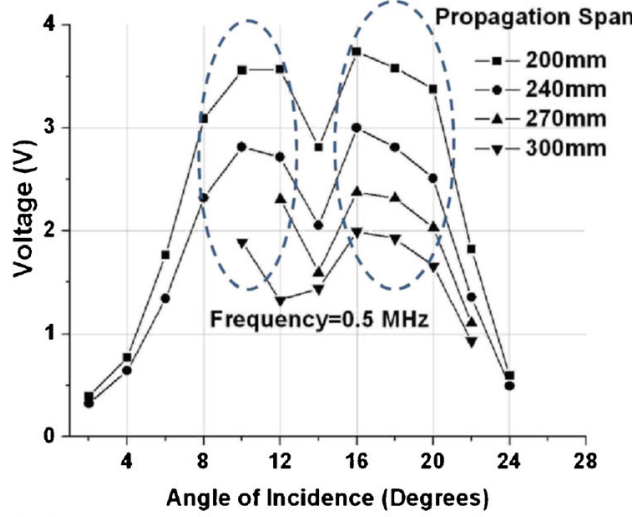

(a)

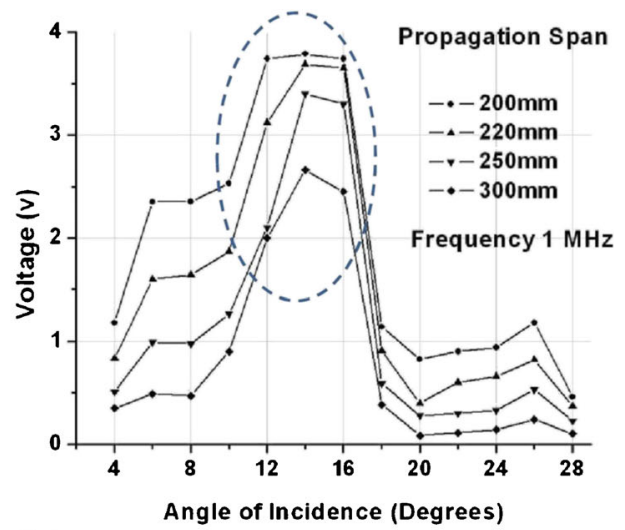

(b)

Figure 13. Angle of incidence $(\theta)$ vs. transmissted pulse amplitudes at varying propagation spans at $0.5 \mathrm{MHz}$ and $1 \mathrm{MHz}$. 


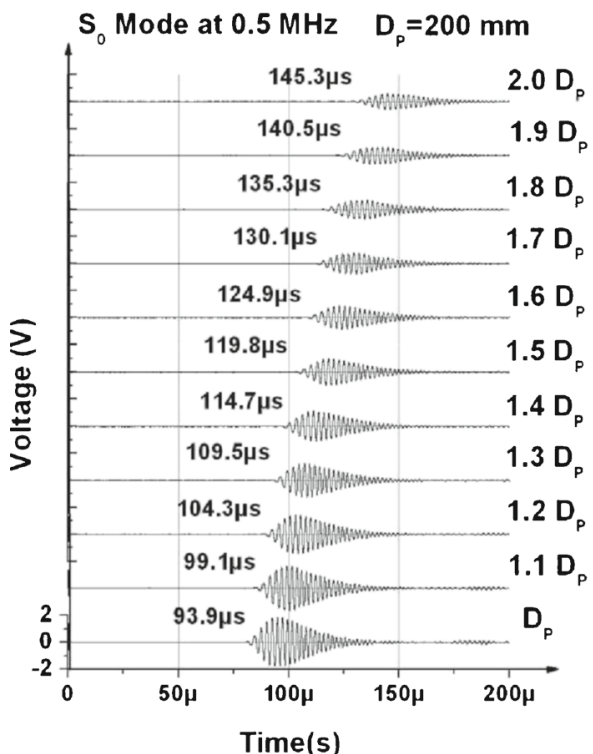

(a)

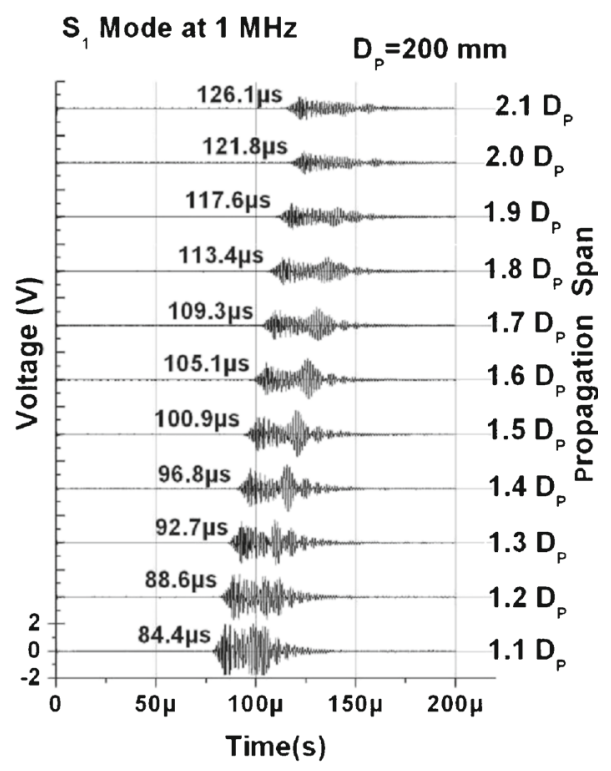

(b)

Figure 14. Pulse transmission signatures with increasing propagation spans (a) $\mathrm{S}_{0}$ Mode at $0.5 \mathrm{MHz}$; (b) $\mathrm{S}_{1}$ Mode at $1 \mathrm{MHz}$.

$200 \mathrm{~mm}$ and the PT signatures are recorded. Subsequently, $\mathrm{D}_{\mathrm{p}}$ is increased in steps of $20 \mathrm{~mm}$ and the PT signatures are recorded at each incremented position. Figure 14 shows stack of such PT signatures recorded with increasing propagation distances for $S_{0}$ mode at $0.5 \mathrm{MHz}$ and $\mathrm{S}_{1}$ mode at $1 \mathrm{MHz}$. It is clear that the envelope of the waves characterizing the selected mode remains unaltered with the change in propagation distance. However, their arrival time increases as the propagation path gets longer since the group velocity of a particular mode through the steel plate is constant. Also the voltage amplitude of the transmitted pulse falls with increasing distance.

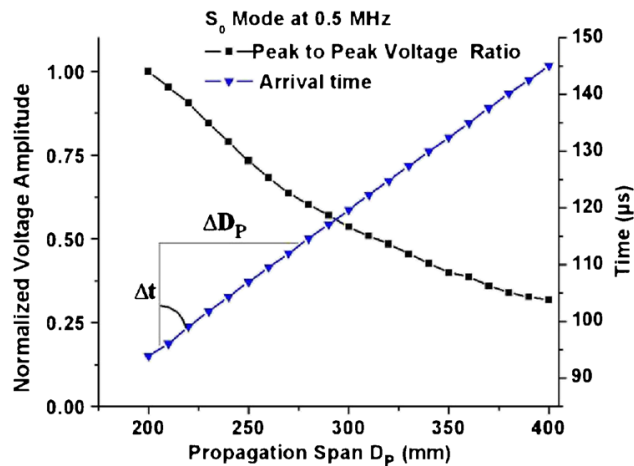

(a)

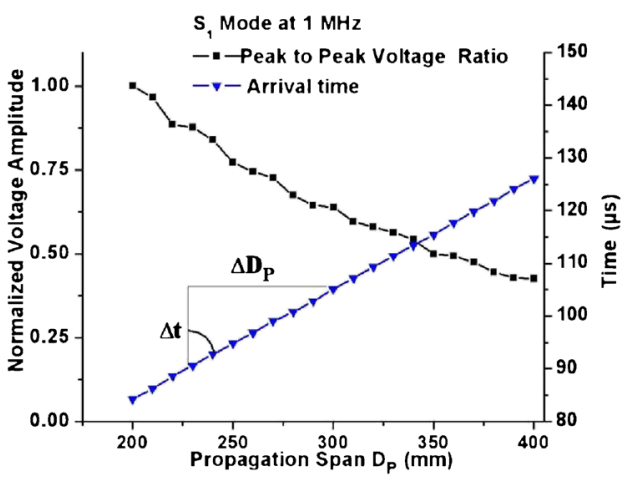

(b)

Figure 15. Variation in peak to peak voltage ratio and time of arrival with increasing propagation span. (a) $\mathrm{S}_{0}$ Mode at $0.5 \mathrm{MHz}$; (b) $\mathrm{S}_{1}$ Mode at $1 \mathrm{MHz}$. 


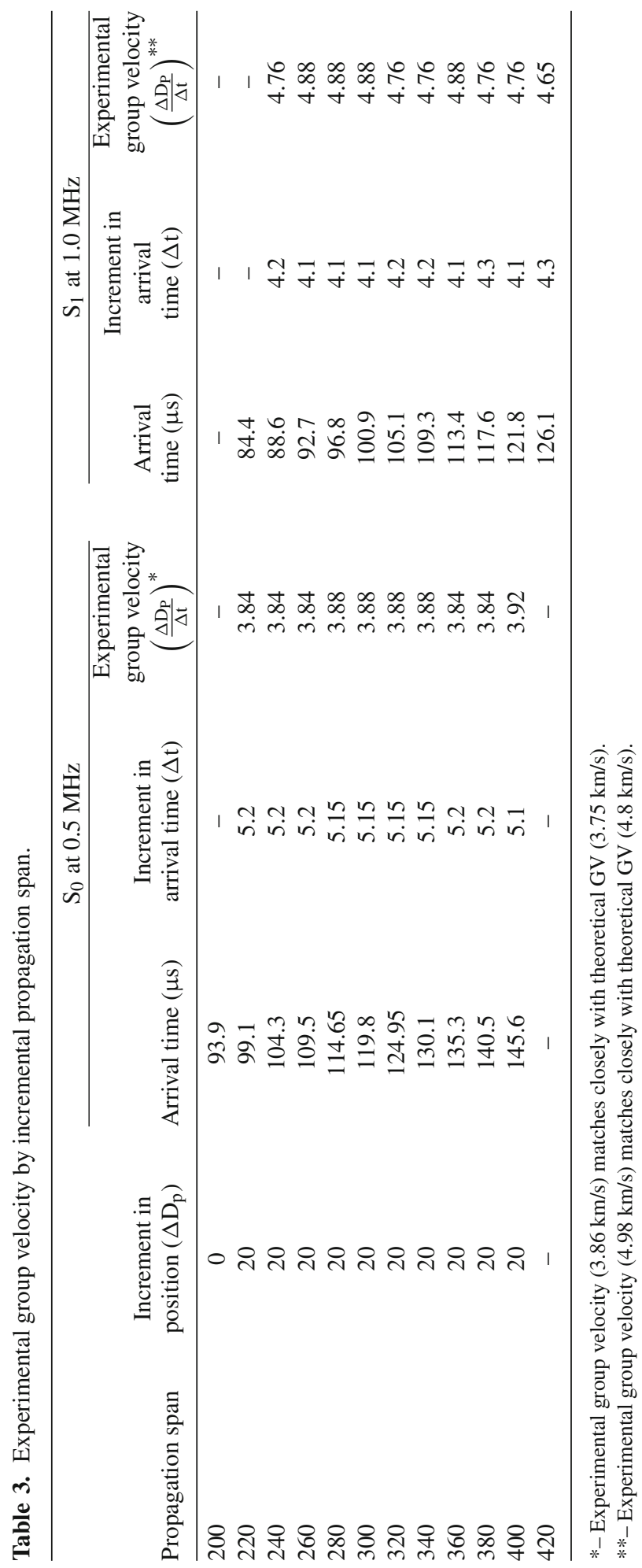


The variation in the arrival time and the normalized voltage amplitude of the transmitted pulse with increasing propagation distances for both $\mathrm{S}_{0}$ mode at $0.5 \mathrm{MHz}$ (figure 15a) and $\mathrm{S}_{1}$ mode at $1 \mathrm{MHz}$ (figure 15b) is plotted. It is observed that fall in voltage amplitude is relatively higher for $0.5 \mathrm{MHz}-\mathrm{S}_{0}$ mode in comparison to $1 \mathrm{MHz}-\mathrm{S}_{1}$ mode. This can be explained by attenuation characteristics of these Lamb wave modes as obtained from attenuation dispersion curves (figure 9c). Attenuation for $\mathrm{S}_{1}$ mode at $1 \mathrm{MHz}$ is quite low $(0.18 \mathrm{~dB} / \mathrm{m})$ as compared to $\mathrm{S}_{0}$ mode at $0.5 \mathrm{MHz}(69 \mathrm{~dB} / \mathrm{m})$. So voltage amplitude for $\mathrm{S}_{0}$ mode falls more sharply as compared to $\mathrm{S}_{1}$ mode.

The variation of arrival time with $\mathrm{D}_{\mathrm{p}}$ was found to be linear. It illustrates that the group velocity of this mode is constant irrespective of the propgation distance. The shifts in the arrival time of

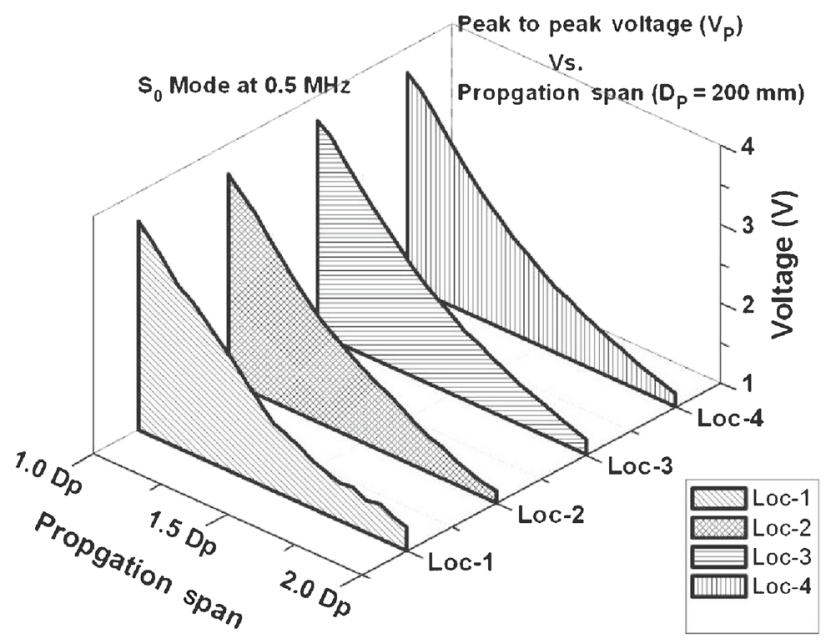

(a)

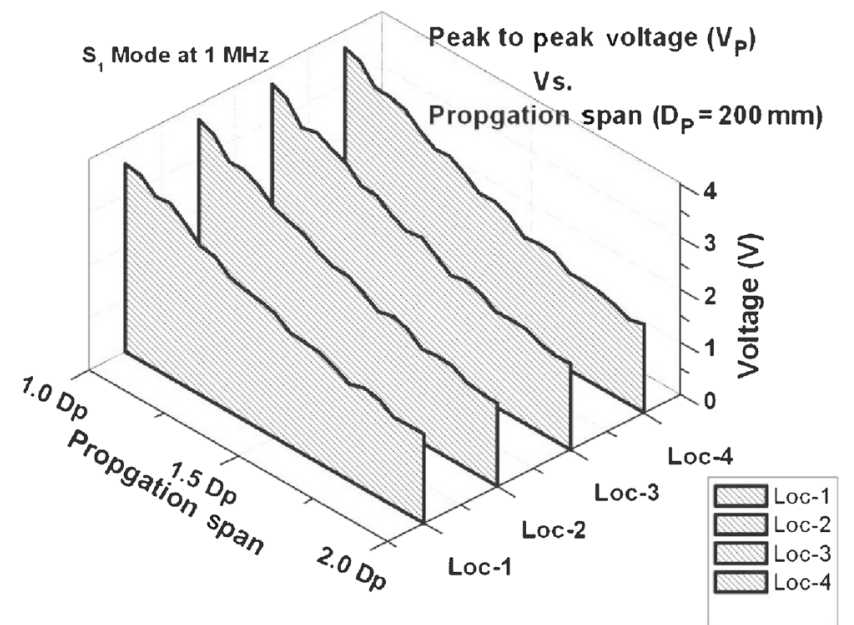

(b)

Figure 16. Variation in peak to peak voltage amplitude with increasing propagation span at different locations on the specimen. (a) $\mathrm{S}_{0}$ Mode at $0.5 \mathrm{MHz}$; (b) $\mathrm{S}_{1}$ Mode at $1 \mathrm{MHz}$. 
the pulse with increments in propagation distance can be used to determine the group velocity of the corresponding Lamb wave mode experimentally from the slope of arrival time-distance graph (Figure 15).

$$
\text { Group velocity }=\frac{\Delta \mathrm{D}_{\mathrm{P}}}{\Delta \mathrm{T}} .
$$

Table 3 shows the group velocity computations for the selected modes by using Eq. (4). The experimental group velocities of the selected modes match reasonably well with the theoretical group velocity values as indicated in dispersion curves (figure $9 b$ ).

In order to ensure repeatibility, the experimentation was carried out at different locations on the plate. Voltage $\left(V_{p}\right)$ amplitudes at these locations with increasing $D_{p}$ is shown in figure 16 . Clearly the variation in voltage amplitudes $\left(V_{p}\right)$ with increasing $D_{p}$ is consistent and repeatable at various locations. The fall in voltage amplitude for $S_{0}$ mode is steeper as compared to $S_{1}$ mode. This trend is also repeated at various locations.

\section{Damage detection in plate with notch}

\subsection{Experimental details}

The effect of a vertical notch on the guided wave propagation characteristics in submerged plate has been examined in this study. A mild steel plate specimen $(70 \mathrm{~mm} \times 200 \times 4 \mathrm{~mm}$ thick $)$ is chosen. PT testing was carried out at locations of the plate as marked in figure 17. Selected Lamb wave modes namely $\mathrm{A}_{1}\left(8.85^{\circ}\right)$ and $\mathrm{S}_{0}\left(17.4^{\circ}\right)$ at $0.5 \mathrm{MHz}$ and $\mathrm{S}_{1}$ mode $\left(14.7^{\circ}\right)$ at $1 \mathrm{MHz}$ have been used. The probes are placed in pitch catch orientation, set at appropriate angle of incidence and separated from submerged plate with $\mathrm{t}_{\mathrm{w}}=40 \mu \mathrm{s}$. For each of the above mentioned Lamb wave modes, PR settings are selected so as to get the maximum amplitude of the transmitted pulse. These settings and the $t_{\mathrm{w}}$ remain unchanged throughout the experimentation.

PT signatures have been first recorded in the healthy plate. Subsequently, a notch, $1.5 \mathrm{~mm}$ wide and $0.5 \mathrm{~mm}$ deep (12.5\% of the plate thickness) was machined on the plate (figure 17) and PT signatures were recorded again. Depth of the notch is then incremented in steps of 25, 37.5, $50,62.5$ and $75 \%$ of the thickness of the plate (figure 18). PT signatures are recorded at each step. The peak to peak voltage amplitude of the transmitted pulse in notched plates is normalized with respect to corresponding peak to peak voltage in the healthy plate. This is necessary in order to compare different modes on the same scale. The normalized voltage amplitudes $\left(\mathrm{V}_{\mathrm{n}}\right)$ are averaged for locations marked as line 1 to line 6 and are presented in table 4 .

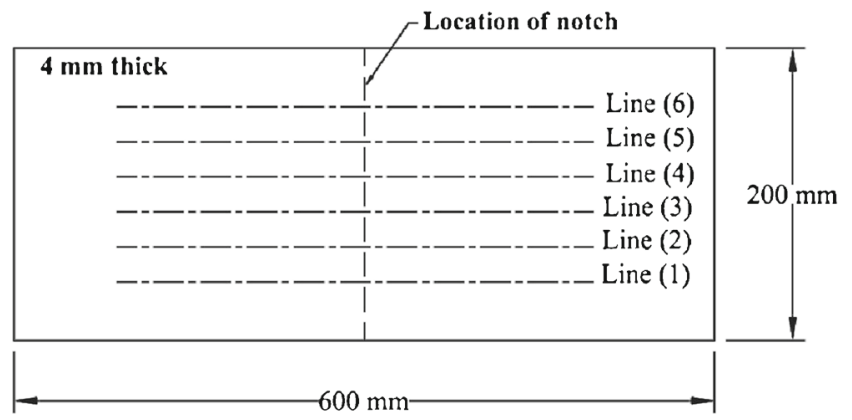

Figure 17. Layout and details of notched plate. 

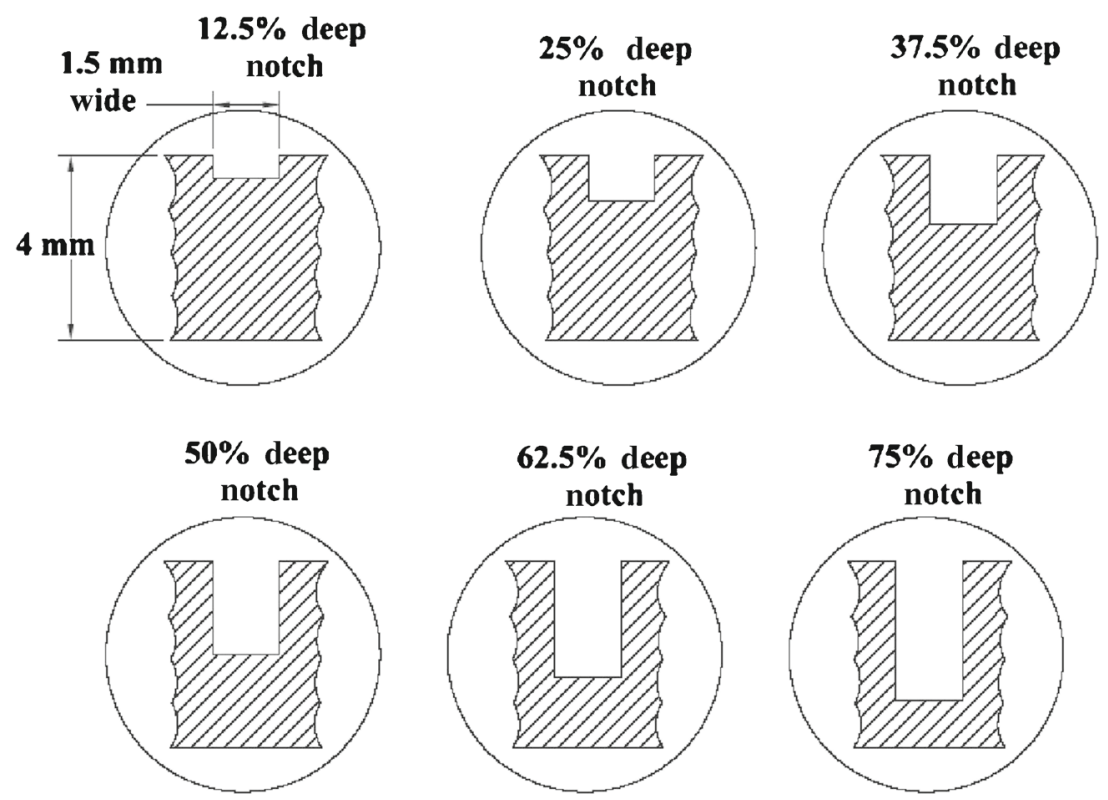

Figure 18. Notch geometry details (1.5 wide and depths varying from 0.5 to $3 \mathrm{~mm}$ with $0.5 \mathrm{~mm}$ increment).

\subsection{Results and discussions}

It is observed that as the percentage depth of notch increases, voltage amplitude of the received signal diminishes. It is due to reflection and scattering of the ultrasonic wave from the notch. With the increase in depth of notch, there is higher attenuation of the signal. Quantitative change in the received signal for the healthy and the notched zone of the plate can be related to the extent of notch depth.

Comparison of responses of selected Lamb wave modes to the notch defect in terms of transmitted pulse amplitudes indicates that different Lamb wave modes have varying sensitivities at different depths of notch. For $\mathrm{S}_{0}$ mode at $0.5 \mathrm{MHz}$, the initial fall in $\mathrm{V}_{\mathrm{n}}$ for notch depth of $12.5 \%$ is $4 \%$ of the healthy voltage amplitude and for $25 \%$ depth of notch; it is $18 \%$. This fall is visibly lower as compared to the fall experienced by the other two modes. This fall is steepest for $\mathrm{S}_{1}$ mode $(53 \%)$ followed by $\mathrm{A}_{1}$ mode $(34 \%)$. However, as the depth of the notch increases, fall in $\mathrm{V}_{\mathrm{n}}$ is relatively higher and consistent for $\mathrm{S}_{0}$ mode as indicated by uniform slope of the corresponding plot line in figure 19. Other two modes i.e., $\mathrm{S}_{0}$ and $\mathrm{A}_{1}$ exhibit relatively lesser change for deeper notches as indicated by the slopes of the corresponding trend lines. Hence, it is clear

Table 4. Normalized voltage amplitude $\left(\mathrm{V}_{\mathrm{N}}\right)$ of transmitted pulse in notched plates.

\begin{tabular}{llllllll}
\hline \multirow{2}{*}{ Mode } & \multicolumn{7}{c}{ Notch depth (\% of plate thickness) } \\
\hline $\mathrm{A}_{1}$ at $0.5 \mathrm{MHz}$ & 1.00 & 0.91 & 0.66 & 0.33 & 0.26 & 0.25 & 0.22 \\
$\mathrm{~S}_{0}$ at $0.5 \mathrm{MHz}$ & 1.00 & 0.96 & 0.82 & 0.66 & 0.53 & 0.39 & 0.23 \\
$\mathrm{~S}_{1}$ at $1 \mathrm{MHz}$ & 1.00 & 0.90 & 0.47 & 0.39 & 0.33 & 0.33 & 0.28 \\
\hline
\end{tabular}




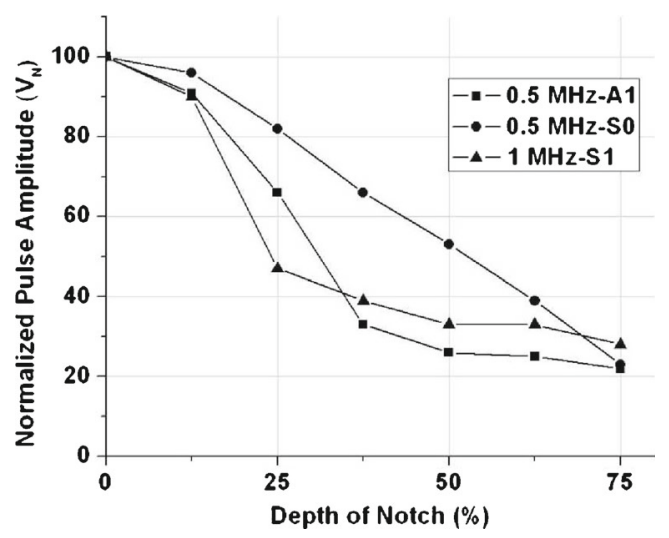

Figure 19. Normalized voltage amplitude Vs. notch depth.

that for deeper notches (depth $>37.5 \%$ of the plate thickness), change in $V_{n}$ for $S_{1}$ and $A_{1}$ modes is negligible whereas $S_{0}$ mode in that range of depth of notch shows substantial fall in $V_{n}$. These variations highlight the efficacy of $S_{1}$ and $A_{1}$ modes for detecting surface defects like corrosion material loss defects. On the other hand, $\mathrm{S}_{0}$ mode at $0.5 \mathrm{MHz}$ is relatively less sensitive to surface change or modifications up to $25 \%$ depth of the plate. But this mode is very useful in identifying the deeper defects varying from 50 to $75 \%$ of the plate depth. It is more suitable for identifying internal defects like internal anomalies, localized pitting defects or fatigue cracks.

Hence, it can be concluded that carefully selected and identified Lamb wave modes can be effectively employed for damage diagnosis in terms of presence and quantification of defect in submerged plate assemblies using the non-contact monitoring system described in this paper.

\section{Conclusions}

The present study is aimed at investigating the propagation characteristics of guided Lamb waves in submerged plate geometries to develop a non-contact, in situ and non-invasive damage monitoring strategy for plate assemblies like ship hulls and marine structures. In such large structures, where the principal motive is detection of defect, this strategy is very promising as a pair of immersion mobile transducers can collect the information about the health of the submerged plate. Specific ultrasonic guided wave modes with unique scanning capabilities have been identified and excited by keeping the transmitter and receiver probes at suitable incident angles and distances in a pitch catch configuration. Drop in voltage $\left(\mathrm{V}_{\mathrm{p}}\right)$ amplitudes of the transmitted signal in these modes could relate to the extent of damage due to notches in the plate. Different modes show different levels of sensitivity to the notches of varying depths. Suitable modes sensitive to near surface and deep notches in the plate have been identified.

\section{Acknowledgements}

The fund received from the Naval Research Board, Defence Research Development Organization (DRDO), Government of India is gratefully acknowledged. Dr Tribikram Kundu, Professor, Department of Civil Engineering and Engineering Mechanics, University of Arizona, Tucson, 
USA visited the health monitoring laboratory in Thapar University on an National Science Foundation Department of Science and Technology (NSF-DST) grant. The authors acknowledge his advice on the study.

\section{References}

Alleyne D N and Cawley P 1991 A 2-dimensional Fourier transform method for the measurement of propagating multi-mode signals. J. Acoustical Soc. Am. 89: 1159-1168

Alleyne D N and Cawley P 1992 Optimization of Lamb waves inspection techniques. NDT \& E Int. 25(1): $11-22$

Ditri J J and Rose J L 1994 Excitation of guided waves in generally anisotropic layers using Finite sources. J. Appl. Mech. 61: 330-338

Guo D and Kundu T 2001 A new transducer holder mechanism for pipe inspection. J. Acoust. Soc. Am. 110: 303-309

Ghosh T, Kundu T and Karpur P 1998 Efficient use of Lamb modes for detecting defects in large plates. Ultrasonics 36: 791-801

Nagy P B, Rose W R and Adler L 1986 Review of Progress in NDE, D O Thompson and D E Chimenti (Eds.) Plenum Press, New York, NY

Pavlakovic B N and Cawley P 2000 DISPERSE User's Manual Version 2.0.1.1, Imperial College, University of London, London

Rose J L 2002a Standing on the Shoulders of Giants - An Example of Guided Wave inspection. Mater. Eval. 60: 53-59

Rose J L 2002b A Baseline and Vision of Ultrasonic Guided Wave Inspection Potential. J. Press. Vessel Technol. 124: 273-282

Rose J L 2003 NDT Solution - Guided wave testing of water loaded structures. Mater. Eval. 60: 23

Rose W R, Rohlin S I and Adler L 1986 Review of Progress in NDE, D O Thompson and D E Chimenti (Eds.) Plenum Press, New York, NY

Sharma S and Mukherjee A 2010 Longitudinal guided waves for monitoring chloride corrosion in reinforcing bars in concrete. Struct. Health Monit. 9(6): 555-567

Sharma S and Mukherjee A 2011 Monitoring corrosion in oxide and chloride environments using ultrasonic guided waves. J. Mater. Civil Eng. 23(2): 207-211 